\title{
Causes of the 2015 North Atlantic cold anomaly in the ECCOv4 state estimates
}

\author{
Rachael N.C. Sanders ${ }^{1}$, Daniel C. Jones ${ }^{1}$, Simon A. Josey ${ }^{2}$, Bablu Sinha ${ }^{2}$, and Gael Forget ${ }^{3}$ \\ ${ }^{1}$ British Antarctic Survey, NERC, UKRI, Cambridge, UK \\ ${ }^{2}$ National Oceanography Centre, Southampton, UK \\ ${ }^{3}$ EAPS, MIT, Cambridge, MA, USA
}

Correspondence: Rachael Sanders (racnde@ bas.ac.uk)

\begin{abstract}
The subpolar North Atlantic is an important part of the global ocean and climate system, with SST variability in the region influencing the climate of Europe and North America. While the majority of the global ocean exhibited higher than average surface temperatures in 2015, the subpolar North Atlantic experienced record low temperatures. This interannual cold anomaly is thought to have been driven by surface forcing, but detailed questions remain about how the anomaly was created and maintained. To better quantify and understand the processes responsible for the cold anomaly, we computed mixed layer temperature budgets in two releases of the ECCO Version 4 global ocean state estimate. These state estimates have been brought into consistency with a large suite of observations without using artificial sources or sinks of heat, making them ideal for temperature budget studies. We found that strong surface forcing drove approximately $75 \%$ of the initial anomalies in the cooling of the mixed layer in December 2013, after which the cold anomaly was sequestered beneath the mixed layer. Reemergence of the cold anomaly during the summer/autumn of 2014 was primarily the result of a strong temperature gradient across the base of the mixed layer, with vertical diffusion accounting for approximately $70 \%$ of the re-emergence. Weaker surface warming of the mixed layer during the summer of 2015 enhanced the anomaly, causing a temperature minimum. Spatial patterns in the budgets also show large differences between the north and south of the anomaly region, with particularly strong initial surface cooling in the south related to the positive phase of the East Atlantic Pattern. It is important to note that this interannual cold anomaly, which is thought to be primarily driven by surface forcing, is distinct from the multi-decadal North Atlantic "warming hole", which is thought to be primarily driven by changes in advection.
\end{abstract}

\section{Introduction}

In 2015, while the majority of the global ocean experienced warmer than average surface temperatures, the subpolar North Atlantic instead experienced record low temperatures. This interannual cold anomaly, often described as the "Atlantic cold blob", is distinct from the multi-decadal cooling trend that has also been observed in the North Atlantic (Drijfhout et al., 2012; Rahmstorf et al., 2015). The cold blob is thought to be driven primarily by surface forcing, while the multi-decadal cooling 
https://doi.org/10.5194/os-2022-10

Preprint. Discussion started: 14 February 2022

trend is thought to be driven primarily by advection. The coldest monthly anomalies occurred during the summer of 2015 , with sea surface temperatures (SSTs) reaching around $2^{\circ} \mathrm{C}$ lower than the long-term average (Duchez et al., 2016; de Jong and de Steur, 2016). The anomaly extended across the subpolar North Atlantic and was observed from the surface to depths of at least $500 \mathrm{~m}$ (Duchez et al., 2016; Josey et al., 2018). The low temperatures led to an increase in convection (Piron et al., 2017) and enhanced formation of Subpolar Mode Water (Grist et al., 2016), with subsequent effects on the local climate (Duchez et al., 2016; Mecking et al., 2019) and surrounding ecosystems (Hátún et al., 2017). The rarity and intensity of the 2015 cold anomaly event, as well as the rate at which the anomaly formed, mean that such events are difficult to predict using models (Maroon et al., 2021).

Previous studies have highlighted the importance of anomalous surface heat loss in driving anomalies in both surface temperatures and the strength of the convection in the North Atlantic (de Jong and de Steur, 2016; Yeager et al., 2016; Desbruyères et al., 2019; Kostov et al., 2021). From 2014-2015, the subpolar North Atlantic experienced the strongest surface heat loss since the 1980s (Yeager et al., 2016). This extreme heat loss spanned the whole subpolar gyre (Piron et al., 2017) and has been linked to anomalously strong westerly and northerly winds transporting colder air over the region (Grist et al., 2016). While there is a strong relationship between variability in upper ocean temperature and the strength of the Atlantic overturning circulation (Desbruyères et al., 2019; Kostov et al., 2021), surface forcing from 2013-14 was strong enough to erode any correlation between the strength of the overturning and the upper ocean heat content (Desbruyères et al., 2019).

Re-emergence, the process by which surface temperature anomalies are "stored" beneath the mixed layer and later brought back up to the surface again as the mixed layer deepens, has also been shown to be important for driving and sustaining temperature anomalies over consecutive years (Alexander et al., 1999). In the North Atlantic, this process involves surfacedriven SST anomalies associated with atmospheric modes of variability, such as the North Atlantic Oscillation (NAO) or East Atlantic Pattern (EAP), being sequestered beneath the seasonal thermocline as the mixed layer shallows during spring/summer. The anomalies then re-emerge at the surface the following autumn/winter, as the mixed layer deepens again (Cassou et al., 2007; Taws et al., 2011).

The 2015 cold anomaly has been linked to the two leading North Atlantic atmospheric modes of variability. The NAO is defined by the pressure gradient between the Iceland Low and Azores High, with a positive index representing a stronger gradient (Rogers, 1984; Lamb and Peppler, 1987). The EAP is recognised by a pressure anomaly in the east of the subpolar gyre, with a negative anomaly associated with a positive EAP index (Wallace and Gutzler, 1981; Barnston and Livezey, 1987). During the strong surface heat loss in the winter of 2013/2014, the EAP was dominant and in its positive phase, while the NAO was dominant and also positive during the winter of 2014/15 (Yeager et al., 2016; Josey et al., 2018). Conversely, variability in the surface temperature of the North Atlantic also has a strong influence on the regional climate, as anomalous SSTs drive changes in atmospheric temperature and subsequent changes in the atmospheric flow (Sutton and Mathieu, 2002). Cold anomalies in the North Atlantic subpolar gyre have also been linked to European heatwaves, and the 2015 cold anomaly may have contributed to the development of extreme heatwave conditions in central Europe during the summer of 2015 (Duchez et al., 2016; Mecking et al., 2019). 
In this work, we compute mixed layer temperature budgets for the region covered by the cold anomaly within two ocean state estimates, in order to gain further understanding of the processes involved in developing and sustaining the North Atlantic cold anomaly. In Section 2, we discuss the two state estimates used to analyse the 2015 cold anomaly, and outline the method used to compute the mixed layer temperature budgets within the models. In Section 3.1, the cold anomaly is analysed within observations in order to validate the cold anomaly within the models in Section 3.2. In Section 3.3, we determine the dominant processes driving seasonal temperature variability within the cold anomaly region, before examining anomalies in these processes in the lead up to, and during, the 2015 cold anomaly in Section 3.4. Finally, in Sections 3.5 and 3.6, the spatial patterns in the processes driving the cold anomaly are explored, focusing particularly on the differences between the north and south of the region.

\section{Methods and data}

\subsection{Ocean state estimates}

We use two MITgcm-based global ocean state estimates to investigate the drivers of the 2015 North Atlantic cold anomaly: Estimating the Circulation and Climate of the Ocean (ECCO) Version 4, Releases 3 (ECCOv4-r3, covering 1992-2015) and 4 (ECCOv4-r4, covering 1992-2017) (Forget et al., 2015a; Fukumori et al., 2017). A state estimate is a numerical simulation of the time-evolving ocean state that has been brought into consistency with a suite of observations (e.g. Argo float profiles, ship hydrography, satellite altimetry). The process of constructing a state estimate involves iteratively adjusting the initial conditions, surface forcing fields, and mixing parameters in order to reduce model-data misfit. The adjustments are carried out via the 4D-Var method, whereby adjoint sensitivity fields are used to calculate the adjustments that will decrease the modeldata misfit. Below we describe some relevant features of these state estimates; we refer the reader to Forget et al. (2015a) and references therein for more details.

ECCOv4 uses a latitude-longitude-cap (LLC) grid with a nominal horizontal resolution of $1 \times \frac{1}{3}-1^{\circ}$, which corresponds to roughly $40-50 \mathrm{~km}$ at high latitudes and roughly $110 \mathrm{~km}$ at the equator. In the vertical, it uses the $\mathrm{z}^{*}$ rescaled height coordinate, with 50 vertical levels ranging from $10 \mathrm{~m}$ to $456 \mathrm{~m}$. ECCOv4 features parameterized diffusion, including simple convective adjustment, diapycnal and isopycnal diffusion, and the Gaspar-Gregoris-Lefevre mixed layer turbulence closure scheme (Gaspar and Gréegoris, 1990). It also includes the bolus transport parameterization of Gent and Mcwilliams (GM, 1990). Despite the relatively coarse resolution of ECCOv4, its water mass properties are in good agreement with observations, thanks in part to the 4D-Var optimization process that iteratively adjusts the spatially varying turbulent transport coefficients (Forget et al., 2015b). As a first guess, ECCOv4 uses ERA-Interim atmospheric forcing fields, which are then adjusted to reduce model-data misfit. The buoyancy, radiative, and mass fluxes use the bulk formulae of Large and Yeager (2009). The state estimate also uses fully dynamic sea ice, with buoyancy and mass fluxes recalculated according to Losch et al. (2010). Note that this setup does not use salinity restoring at the surface.

Although the two releases of ECCOv4 are similar, there are some important differences between them. These include the algorithm used for numerical stability, the weighting used for hydrographic profiles, and an increase in the observational data 
used in ECCOv4-r4 in comparison to ECCOv4-r3 (ECCO Consortium et al., 2021, see Table 2). We use the two releases to show that the results are insensitive to the changes in model setup; the differences between them do not influence the ability to reproduce the 2015 cold anomaly within the model, nor do they affect the conclusions on the drivers of the cold anomaly. However, a detailed analysis of how the model differences lead to differences in the representation of the cold anomaly is outside the scope of this paper.

\subsection{Mixed layer temperature budget}

We compute mixed layer temperature budgets for the North Atlantic using a well-established analysis method (e.g. Frankignoul, 1985; Peter et al., 2006; Dong et al., 2007), as described in Equation 1 below. We define the mixed layer depth (MLD), $h_{m}$, as the depth at which potential density is $0.03 \mathrm{~kg} \mathrm{~m}^{-3}$ greater than that of the surface cell. The net rate of change in the average mixed layer temperature, $T_{m}$, is attributed to surface heat fluxes, horizontal advection, entrainment of water from beneath the mixed layer, vertical and horizontal diffusion, and lateral induction, which describes the horizontal transport of water through the base of a sloped mixed layer:

$$
\frac{\partial T_{m}}{\partial t}=\underbrace{\frac{Q_{n e t}-q\left(h_{m}\right)}{\rho_{0} c_{p} h_{m}}}_{\text {Surface flux }}-\underbrace{\mathbf{u}_{\mathbf{m}} \cdot \nabla T_{m}}_{\text {Advection }}-\underbrace{\frac{\partial h_{m}}{\partial t} \frac{\Delta T}{h_{m}}}_{\text {Entrainment }}-\underbrace{\mathbf{u}_{\mathbf{m}} \cdot \nabla h_{m} \frac{\Delta T}{h_{m}}}_{\text {Lateral induction }}+\underbrace{\frac{K_{z}}{h_{m}} \frac{\Delta T}{\Delta z}}_{\begin{array}{c}
\text { Vertical } \\
\text { diffusion }
\end{array}}+\underbrace{\kappa \nabla^{2} T_{m}}_{\begin{array}{c}
\text { Horizontal } \\
\text { diffusion }
\end{array}} .
$$

$Q_{n e t}$ is the net heat flux into the surface ocean, and $\rho_{0}$ and $c_{p}$ are constants denoting reference density and specific heat capacity. The decay of incoming shortwave radiation within the top depth cells is represented by the function $q$ (Chakraborty and Campin, 2013). $\boldsymbol{u}_{m}$ is the lateral ocean velocity averaged over the mixed layer, and $\Delta T$ is the difference between the average temperature of the mixed layer and that of the model depth cell immediately below. The entrainment velocity is defined as the rate of change in MLD, but this is set to zero for a shallowing mixed layer, since detrainment does not alter the properties of the remaining water in the mixed layer.

In the ECCOv4 state estimate, the spatially-varying values for horizontal and vertical diffusivity are adjusted as part of the state estimation process. In the mixed layer budget, we use constant diffusivity values for simplicity. The values were optimized in order to minimize the average error between the right and left hand sides of the equations within the region of the cold anomaly. We therefore use a vertical diffusivity, $K_{z}$, of $1.81 \times 10^{-4}$ and $2.01 \times 10^{-4} \mathrm{~m}^{2} \mathrm{~s}^{-1}$ for ECCOv4-r3 and ECCOv4-r4 respectively, and horizontal diffusivities $\kappa$ of $2000 \mathrm{~m}^{2} \mathrm{~s}^{-1}$ for both state estimates.

This method to compute the mixed layer temperature budget results in an approximation of the budget, while taking into account the dynamic nature of the mixed layer via the inclusion of entrainment and lateral induction terms, which are driven by the spatio-temporal changes in the depth of the mixed layer. By defining the individual terms this way, we can deconstruct those relevant to the formation of the cold anomaly to further understand the processes and properties that result in anomalies in the budget terms. Using Equation 1, the mixed layer temperature budget was computed at each individual point within the entire area covered by the North Atlantic cold anomaly, defined as $50-20^{\circ} \mathrm{W}, 43-63^{\circ} \mathrm{N}$ (shown in Fig. 1), the approximate area covered by the 2015 anomaly. For comparison, fully closed budgets were also computed online for each model, using the 

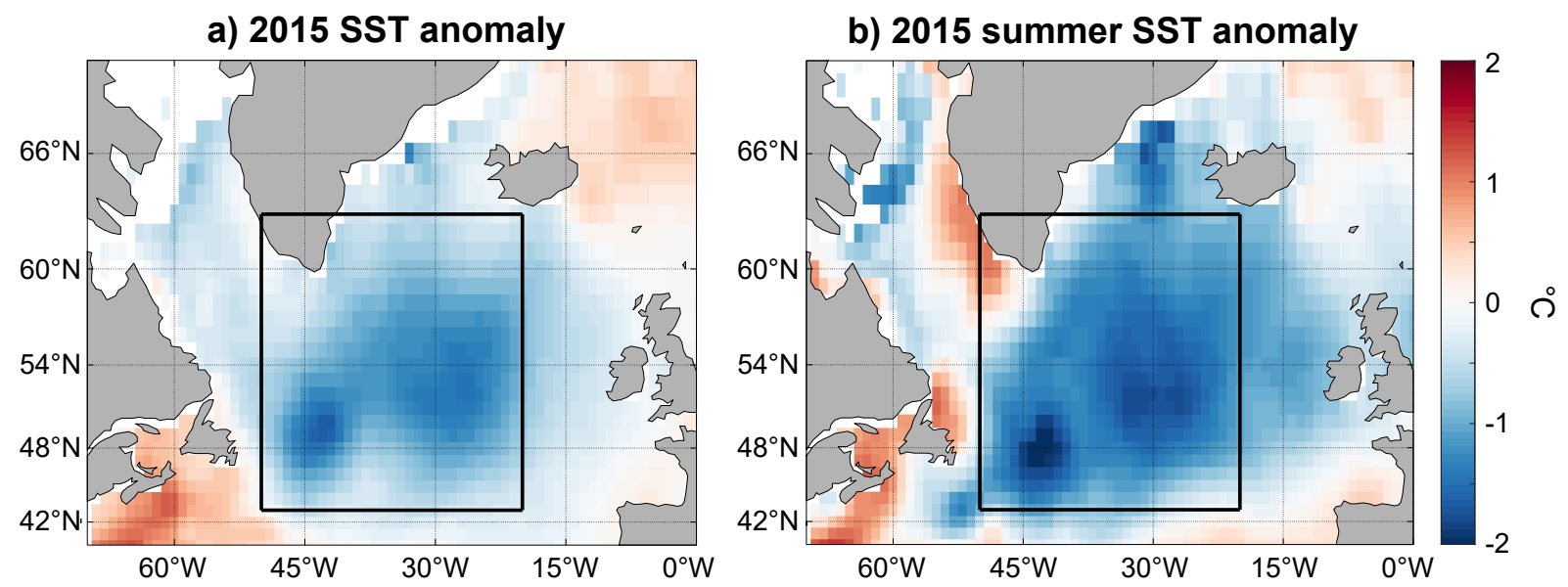

Figure 1. The SST anomaly $\left({ }^{\circ} \mathrm{C}\right)$ in the HadISST1 monthly SST observations, relative to the 1992-2015 climatology (i.e. the period covered by the two state estimates used in this study), averaged over a) the whole of 2015 and b) the summer (JJA) only. The black boxes mark the region we use to define the extent of the 2015 cold anomaly $\left(50-20^{\circ} \mathrm{W}, 43-63^{\circ} \mathrm{N}\right)$.

output advection and diffusion terms following the steps set out by Piecuch (2017). The budget terms for each cell within the mixed layer were then averaged at each timestep to replicate the terms of the approximated mixed layer budget. The surface heat flux term of the budget is computed in the same way for each method, however the fully closed budget does not include the entrainment or lateral induction terms and so does not factor in the changing depth of the mixed layer. The results of these closed budgets are shown in the Appendix.

\section{Results}

\subsection{The 2015 cold anomaly in observations}

We first analyse the 2015 cold anomaly in observations, for comparison with the cold anomaly in the state estimates. The average anomalies in the HadISST1 monthly averaged SST observations are shown in Fig. 1. Negative SST anomalies are present across the majority of the North Atlantic and are more intense when only the summer is considered. The coldest anomalies, of around $-2^{\circ} \mathrm{C}$, occur in the southwest of the region, centred at approximately $44^{\circ} \mathrm{W}, 48^{\circ} \mathrm{N}$. The boxes shown in Fig. 1 represent the region that encompasses the majority of the cold anomaly. While the negative anomalies extend slightly further east and north, the strongest anomalies are contained within the box. In the northwest of the box, along the southwest Greenland coast, positive (warm) anomalies are only present during the summer, so do not strongly affect the 2015 annual average. 
a) ECCOv4-r3

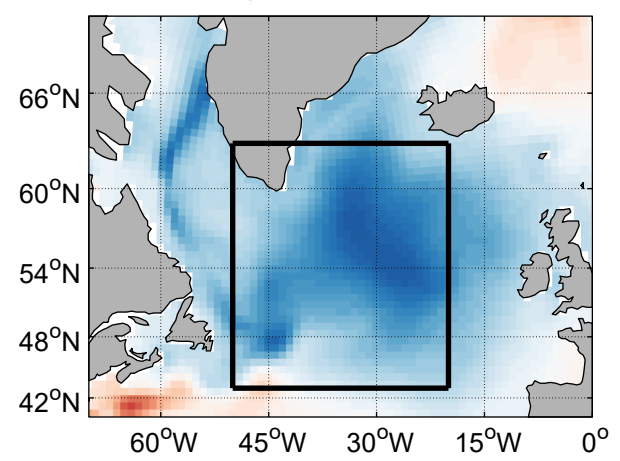

c) ECCOv4-r4

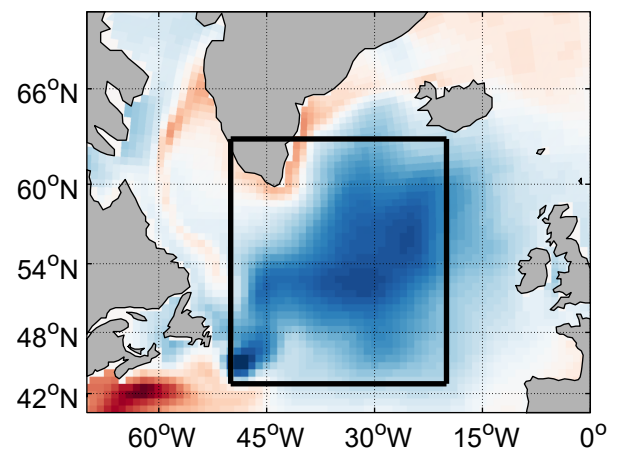

b) ECCOv4-r3: summer

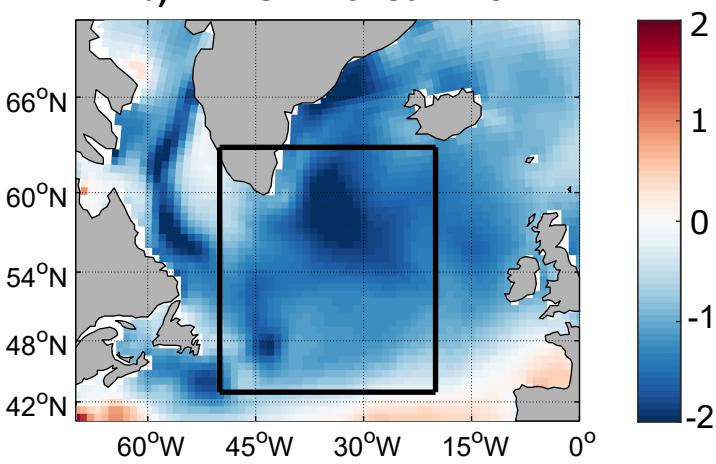

d) ECCOv4-r4: summer

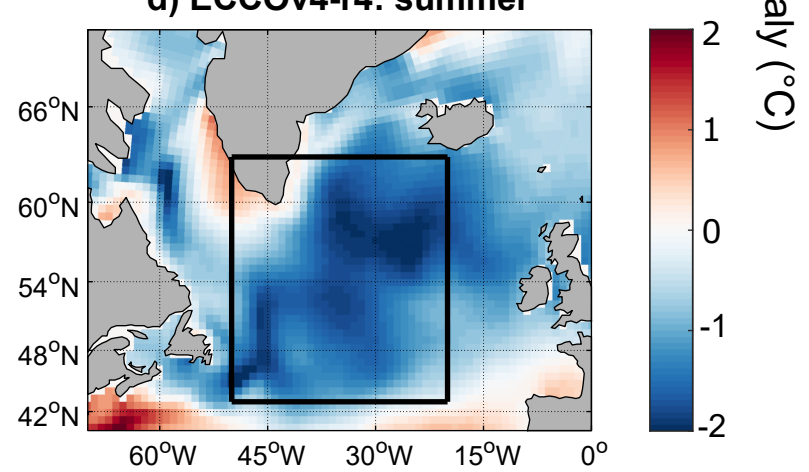

Figure 2. The average 2015 SST anomaly (left), and the average 2015 summer (JJA) SST anomaly (right), relative to the $1992-2015$ monthly climatology $\left({ }^{\circ} \mathrm{C}\right)$ in the state estimates: a,b) ECCOv4-r3, and c,d) ECCOv4-r4. The boxes mark the same region as those in Fig. 1, defining the approximate extent of the 2015 cold anomaly.

\subsection{The 2015 cold anomaly in the state estimates}

The 2015 cold anomaly is present in the SST of both state estimates (Fig. 2). As in the observations, the SST anomalies are most strongly negative when only the summer of 2015 is considered, but a clear cold anomaly is also seen when the anomalies are averaged over the whole year. The state estimates capture the overall pattern of the 2015 cold anomaly, especially within the box focused on throughout this study, although there are some spatial differences. In ECCOv4-r3, negative SST anomalies occur throughout the box in the 2015 average (Fig. 2a), with slight positive anomalies further to the northeast and southwest, agreeing with observations. When averaged over summer only (Fig. 2b), the differences from the observations are clearer, with negative anomalies across the region but with a centre towards the north of the box rather than the southwest. In ECCOv4-r4, the negative anomaly in the 2015 average is similar to that of observations within the box (Fig. 2c), except for slight positive anomalies along the southern coast of Greenland. Positive anomalies also occur in the Labrador Sea when the SST anomaly is averaged over the whole of 2015. However, in both the models and observations, the sign of the anomalies in this region is strongly dependent on the period over which the subtracted climatology is calculated. The positive anomalies in ECCOv4-r4 


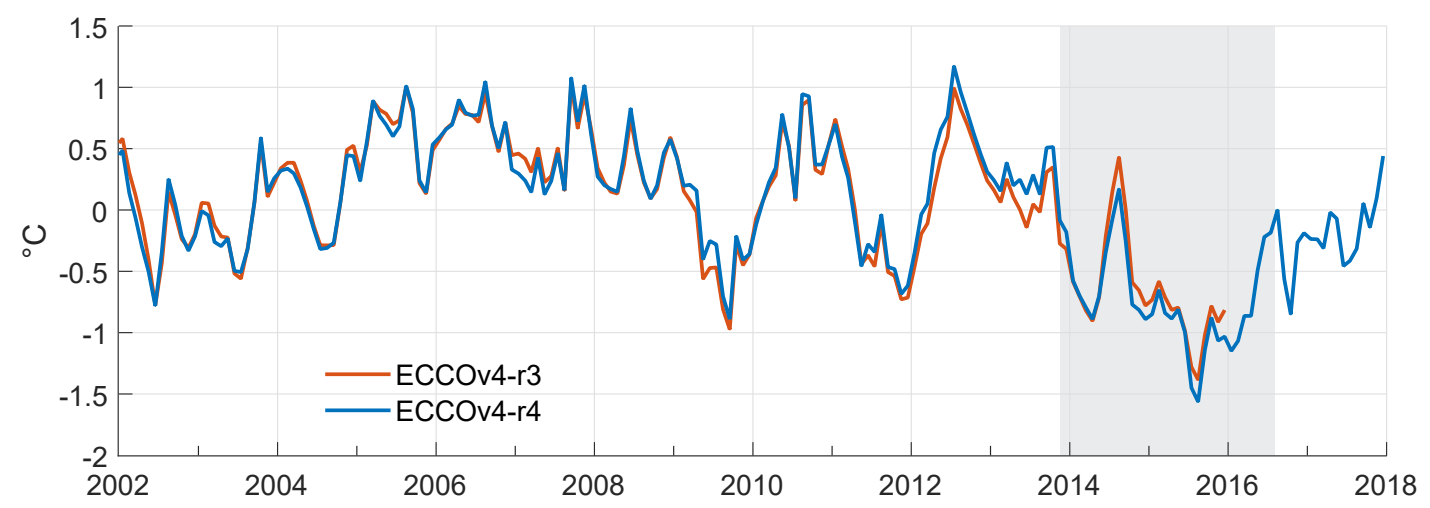

Figure 3. Time series of anomalies in the mixed layer average potential temperature $\left({ }^{\circ} \mathrm{C}\right)$, relative to the $1992-2015$ monthly climatology, averaged over the cold blob region, for ECCOv4-r3 (red) and ECCOv4-r4 (blue). The shaded area marks the time period from when the initial cold anomaly begins to emerge to when the anomaly once again becomes positive.

are driven by warming from January to April, but when only summer is considered, the anomalies in this region are much closer to the observations (Fig. 2d).

In this work, we focus only on the anomalies within the box shown. Because the anomaly has no regular shape, and to remove the effect of the warm anomalies along the Greenland coast in ECCOv4-r4 that are not seen in observations, we define the cold blob region as the area within the selected control volume with an average 2015 SST anomaly below zero. The results of the mixed layer temperature budgets are insensitive to the inclusion of these areas. When the SST anomaly is averaged over this region, the $\mathrm{R}^{2}$ values between the time series of anomalies in HadISST1 observations and the state estimates are 0.92 for ECCOv4-r3 and 0.94 for ECCOv4-r4, for the period 1992-2015.

We focus on the cold anomaly within the mixed layer. The time series of the mixed layer temperature anomalies averaged over the cold blob region is therefore shown for each state estimate in Fig. 3. The 2015 cold anomaly is clear in the mixed layer temperature as the most negative anomalies over the time series, and there is little difference between the two state estimates $\left(\mathrm{R}^{2}\right.$ $=0.96$ ). Negative temperature anomalies first appear in November 2013 , decreasing to $-0.9^{\circ} \mathrm{C}$ in April 2014 , before switching to positive anomalies from July to September 2014. The anomalies then become negative again and decrease strongly, reaching a minimum of $-1.4^{\circ} \mathrm{C}$ in ECCOv4-r3 and $-1.6^{\circ} \mathrm{C}$ in ECCOv4-r4 in August 2015. The linear trend in the anomalies in mixed layer temperature from the start of the cooling (December 2013) to the peak cold anomaly (August 2015) is $-0.40^{\circ} \mathrm{C}^{-1}$ in ECCOv4-r3, and $-0.48^{\circ} \mathrm{C} \mathrm{yr}^{-1}$ in ECCOv4-r4. The anomalies then remain predominantly negative throughout 2016 and 2017. The linear trend in the anomalies from the peak of the anomaly until the end of the ECCOv4-r4 time series (December 2017) is $0.56^{\circ} \mathrm{C} \mathrm{yr}^{-1}$.

There are clear signatures of re-emergence in the vertical structure of the temperature anomalies and the MLD (Fig. 4). The anomaly begins in the winter of 2013/14, and reaches a minimum within the shallow summer 2015 mixed layer. During 2013, weak warm temperature anomalies extend through the water column, before cold anomalies develop in the winter of 2013/14, extending throughout the deep winter mixed layer. The following summer, the mixed layer shallows and the negative 
a) ECCOv4-r3

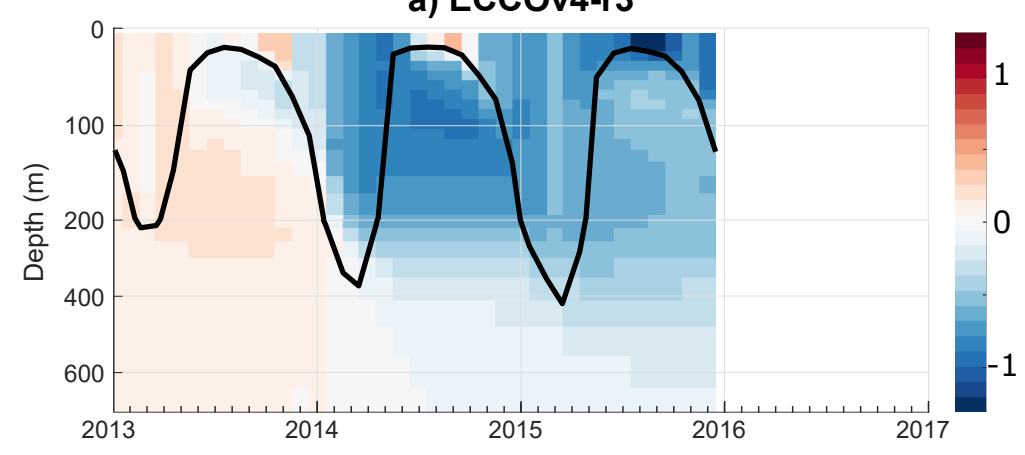

b) ECcOv4-r4

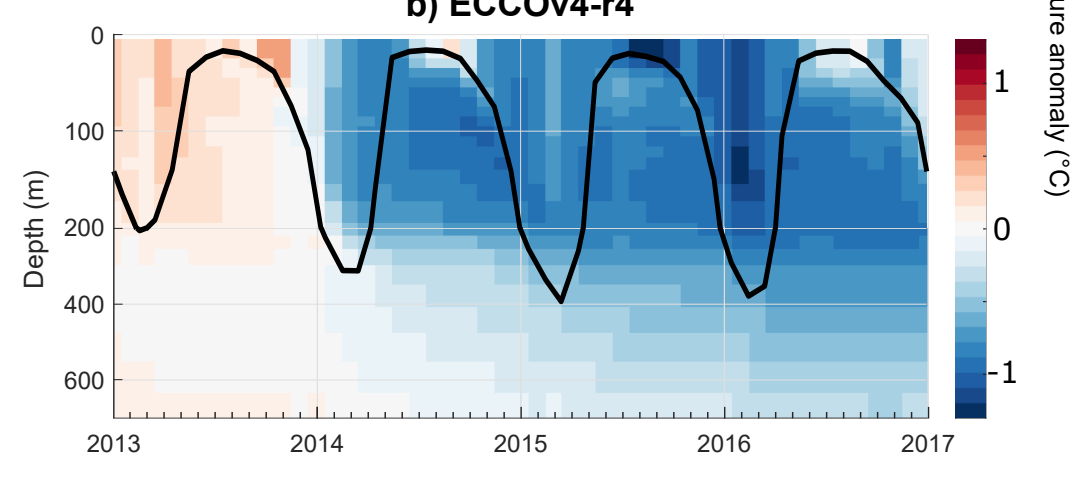

Figure 4. The potential temperature anomaly over depth relative to the 1992-2015 monthly climatology (color; ${ }^{\circ} \mathrm{C}$ ), averaged over the cold blob region in a) ECCOv4-r3 and b) ECCOv4-r4. The MLD is also shown (black line, $m$ ). Note the non-uniform spacing of the vertical axes.

anomalies are sequestered beneath, where they continue to decrease slowly. During this time, the mixed layer temperature instead experiences positive (warm) anomalies, as seen within the average mixed layer temperature in Fig. 3. In October 2014, the mixed layer starts to deepen again and the cold anomaly re-emerges within the mixed layer. Further cooling occurs during the summer of 2015, with the minimum temperature occurring in each model within the shallow summer mixed layer. Following the minimum, the cold anomaly is sustained through 2016 at a lesser magnitude (past the end of the ECCOv4-r3 time series), and is again sequestered below the mixed layer during the summer when very small anomalies are seen within the shallow mixed layer. In general, both the warm anomalies prior to the formation of the cold anomaly, and the cold anomaly itself, are more intense in ECCOv4-r4. However, there is still very little difference between the two models when the average temperature of the mixed layer is considered (Fig. 3). At its deepest, the cold anomaly extends from the surface to depths of at least $500 \mathrm{~m}$. During the formation of the cold anomaly, the depth of the winter mixed layer within the cold blob region also increases. The MLD peaks in 2015 with a maximum depth in each model time series of $419 \mathrm{~m}$ in ECCOv4-r3, and 393 m ECCOv4-r4 during March 2015. This increase in MLD is potentially a result of the the cold anomaly driving increased convection. 
a) ECCOv4-r3

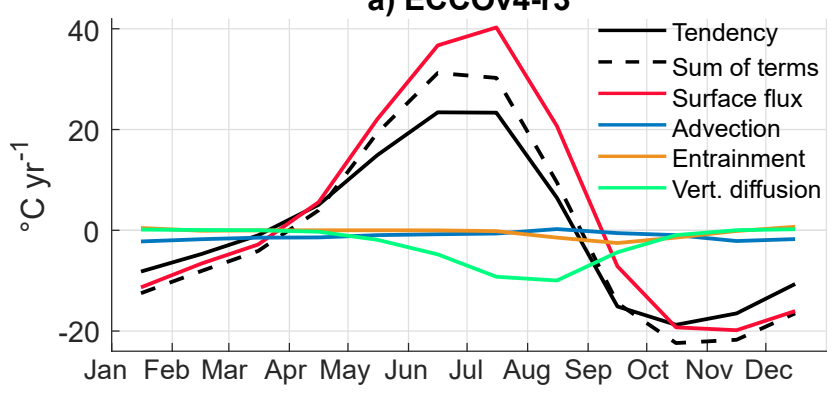

b) ECCOv4-r4

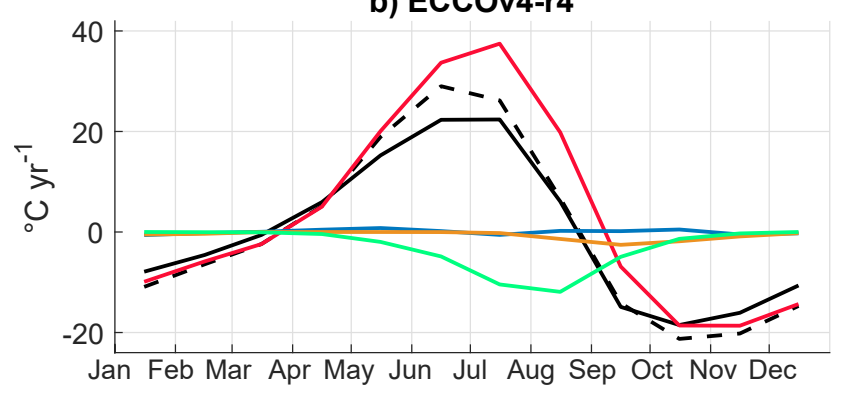

Figure 5. The average seasonal cycle of the dominant mixed layer temperature budget terms $\left({ }^{\circ} \mathrm{C} \mathrm{yr}^{-1}\right)$ averaged over the cold blob region for a) ECCOv4-r3 and b) ECCOv4-r4, where positive values represent an increase in the rate of change in the temperature of the mixed layer. The black solid line shows the actual temperature tendency in the model, and the dashed line shows the sum of the budget terms driving that temperature change. The remaining lines represent the temperature change due to each individual process: surface heat fluxes (red), horizontal advection (blue), vertical entrainment (orange), and vertical diffusion (green). Horizontal diffusion and lateral induction are not shown as the effects of both are negligible.

\subsection{Processes driving seasonal temperature variability in the cold blob region}

To determine the processes controlling temperature variability within the cold blob region, the average seasonal cycle of the mixed layer temperature budget was calculated (Fig. 5). This approach to computing the mixed layer temperature budget takes into account the spatio-temporal variability in MLD, but due to the low temporal resolution of the model data and the various assumptions made in the method, there is a residual between the actual temperature tendency of the mixed layer and the sum of the budget terms driving that tendency. The warming of the mixed layer during summer is slightly overestimated (i.e. the sum of the temperature budget terms is greater than the actual temperature tendency within the model) and the cooling during winter is also overestimated, however the majority of the seasonal temperature variability is captured by the budget in each model. The horizontal diffusion and lateral induction terms are not shown as they have a negligible effect on temperature variability in the cold blob region.

The average seasonal cycle in temperature tendency within the region is dominated by the surface heat flux, which drives a warming of the mixed layer from April to August and a cooling of the mixed layer from September to March. The maximum 
https://doi.org/10.5194/os-2022-10

Preprint. Discussion started: 14 February 2022

seasonal warming due to surface forcing occurs in July $\left(3.4^{\circ} \mathrm{C}_{\text {month }}{ }^{-1}\right.$ in ECCOv4-r3, $3.1^{\circ} \mathrm{C}_{\text {month }}{ }^{-1}$ in ECCOv4-r4) and the maximum cooling occurs in November $\left(-1.7^{\circ} \mathrm{C}_{\text {month }}^{-1}\right.$ in ECCOv4-r3, $-1.6^{\circ} \mathrm{C}$ month ${ }^{-1}$ in ECCOv4-r4). Vertical diffusion is the second most important term, driving a cooling of the mixed layer from approximately May to September, with the maximum cooling occurring from July to August $\left(-0.8^{\circ} \mathrm{C}_{\text {month }^{-1}}\right.$ in ECCOv4-r3, $-1.0^{\circ} \mathrm{C}$ month $^{-1}$ in ECCOv4-r4). This seasonal variability in diffusive cooling is driven by the seasonality in the temperature difference between the mixed layer and thermocline, with a greater difference when the mixed layer is shallow in summer. This relationship is further discussed in section 3.4.

No vertical entrainment occurs from December to July due to the shallowing mixed layer, but entrainment cools the mixed layer from August to October/November, as the mixed layer deepens and entrains colder water from below. In each model, the maximum mixed layer cooling via entrainment occurs in September, when the rate of deepening of the mixed layer is highest. The impact of entrainment is small, causing a maximum cooling of $-0.2^{\circ} \mathrm{C}$ month ${ }^{-1}$ in both models. Advection is also low throughout the year; in ECCOv4-r3, a slight advective cooling of the mixed layer occurs from January to March with a maximum of $-0.2^{\circ} \mathrm{C}$ month ${ }^{-1}$, but is negligible through the rest of the year, and in ECCOv4-r4 advection is always close to zero. While there are some differences between the model results, the dominant processes of the mixed layer temperature budget show very similar seasonal cycles.

\subsection{Processes driving the 2015 cold anomaly}

The 2015 cold anomaly is driven by a combination of surface forcing, vertical diffusion and entrainment, as shown by monthly anomalies in the temperature budget (Fig. 6). Anomalies in these processes are in turn the result of anomalies in the net surface heat flux, the temperature gradient across the base of the mixed layer, and the depth of the mixed layer (Fig. 7). Initial cooling of the mixed layer in the winter of 2013/14 is due to strong negative anomalies in the surface heat flux term, signifying stronger than average surface heat loss. In each model, the strongest surface-driven cooling of the mixed layer is in December 2013, with anomalies of $-0.9^{\circ} \mathrm{C}_{\text {month }}{ }^{-1}$ in ECCOv4-r3 and $-0.7^{\circ} \mathrm{C}_{\text {month }}^{-1}$ in ECCOv4-r4. While the change in temperature due to surface fluxes is dependent on both the net heat flux through the surface and the MLD (see Equation 1), it is strong anomalies in the outgoing flux during December that cause the stronger mixed layer cooling during this period (Fig. 7a), with anomalies of at least $-100 \mathrm{~W} \mathrm{~m}^{-2}$ in each model. This cooling is enhanced by anomalies in advective cooling of the mixed layer, reaching $-0.3^{\circ} \mathrm{C}$ month $^{-1}$ in both models. Advective cooling also peaks in December 2013 and is due to a combination of both zonal and meridional advection. Approximately $75 \%$ of the anomalous initial cooling of the mixed layer is therefore due to surface forcing, while the remaining $25 \%$ is predominantly a result of horizontal advection.

Following the initial cooling, anomalies in each of the main temperature budget terms are then low until April 2014, when higher than average surface warming drives overall positive anomalies in the temperature tendency from April to June (Fig. 6). Since the mixed layer is shallow over this period, while the surface warming acts to increase the average temperature of the mixed layer, it has a relatively small effect on the heat content of the water column. The warming of the mixed layer is also suppressed by strong vertical diffusion, driven by the high temperature difference between the mixed layer and thermocline (Fig. 7c). The temperature difference is greatest during summer when the mixed layer is shallow and heated by strong surface 


\section{a) ECCOv4-r3}

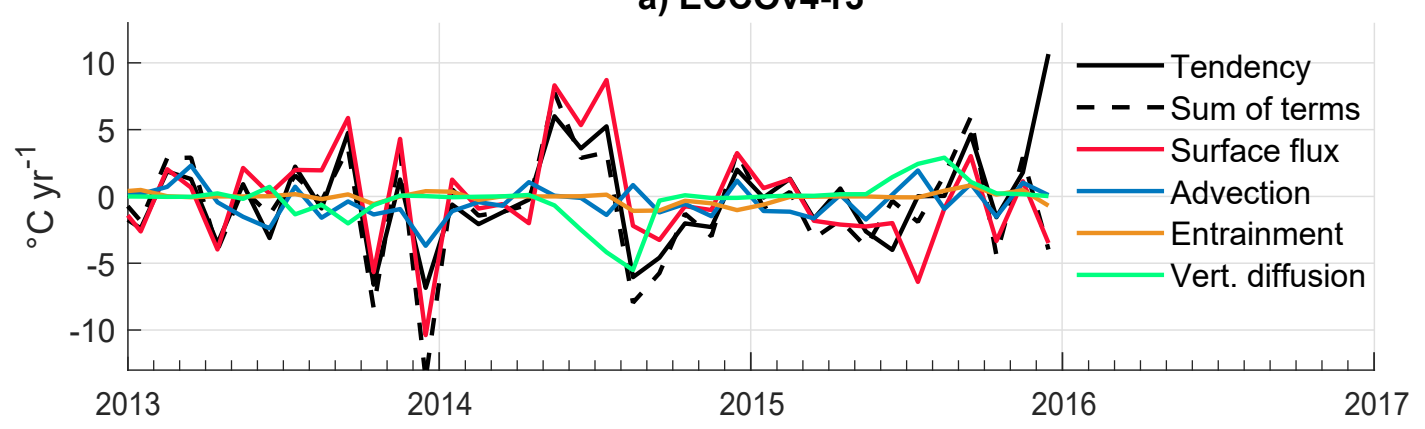

b) ECCOv4-r4

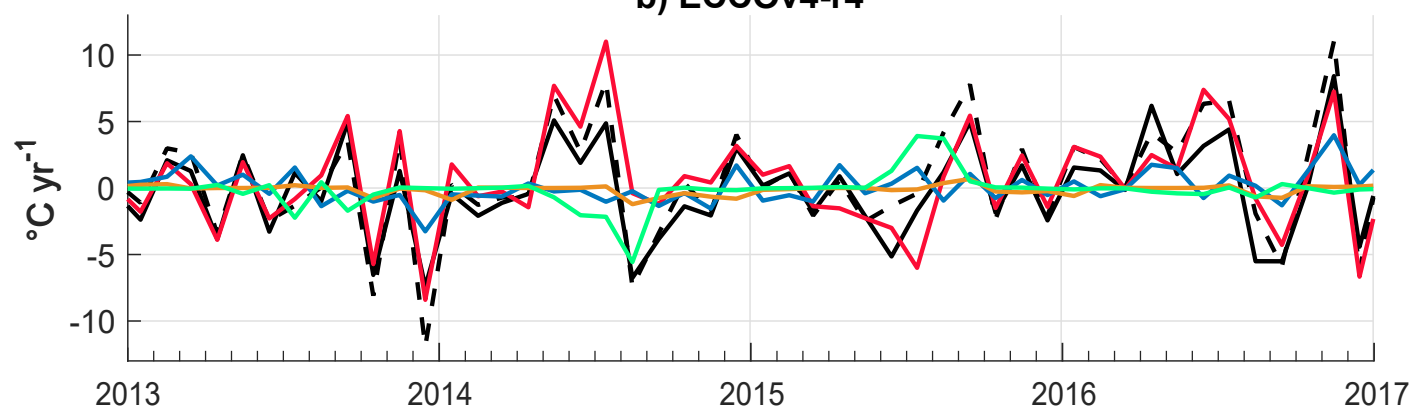

Figure 6. Anomalies in the dominant terms of the mixed layer temperature budget, relative to the $1992-2015$ monthly climatology $\left({ }^{\circ} \mathrm{C} \mathrm{yr}{ }^{-1}\right)$, averaged over the cold blob region. The solid black line shows anomalies in the model temperature tendency, and the dashed black line shows anomalies in the sum of the temperature budget terms driving the temperature change. The remaining lines represent those individual processes: the surface heat flux (red), horizontal advection (blue), vertical entrainment (orange), and vertical diffusion (green). Again, lateral induction and horizontal diffusion are not shown because anomalies in both are negligible.

heat fluxes. The temperature difference then rises from May onwards, driving cooling of the mixed layer via diffusion. The temperature difference peaked in August 2014 with a difference of $1.4^{\circ} \mathrm{C}$ in each model, driving anomalies in diffusive cooling of $-0.5^{\circ} \mathrm{C}_{\text {month }}{ }^{-1}$ in both models. This anomalously strong vertical diffusion is the main cause of the re-emergence of the cold anomaly after being sequestered beneath the mixed layer during spring/summer. The strong summer surface warming of the mixed layer then reduces quickly in August as the anomaly in the net surface heat flux becomes close to zero (Fig. 7a) and the mixed layer deepens.

The re-emergence of the cold anomaly is also enabled by the deepening of the mixed layer, which results in the entrainment of colder water from below. The mixed layer cooling via entrainment in the ECCO models is small, with anomalies peaking during August at $-0.1^{\circ} \mathrm{C}$ month ${ }^{-1}$ in both models. The depth of the mixed layer is not particularly anomalous during the winter of 2014 (Fig. 7b), especially in comparison to the following two years, and the timings of the minima in entrainment anomalies do not always correspond to anomalies in MLD. It is therefore the large temperature difference between the mixed layer and thermocline that drives the re-emergence of the cold anomaly, primarily through vertical diffusion, with the cooling 
a) Net surface heat flux anomalies

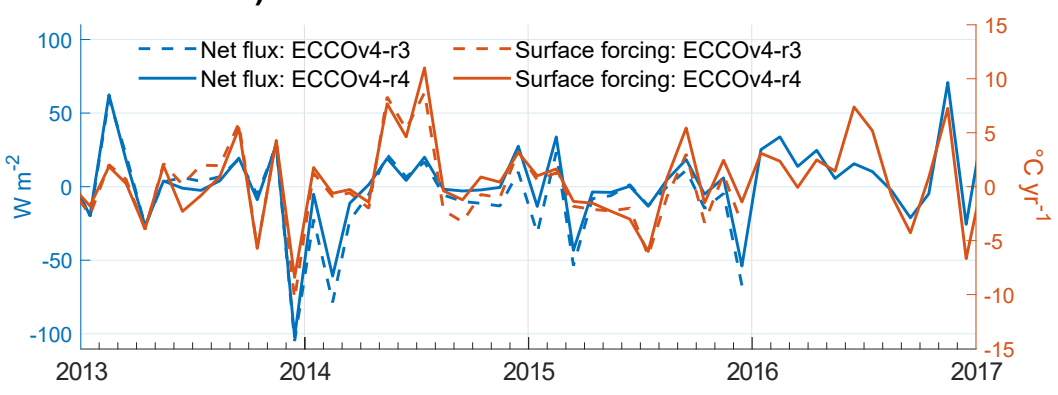

b) MLD anomalies

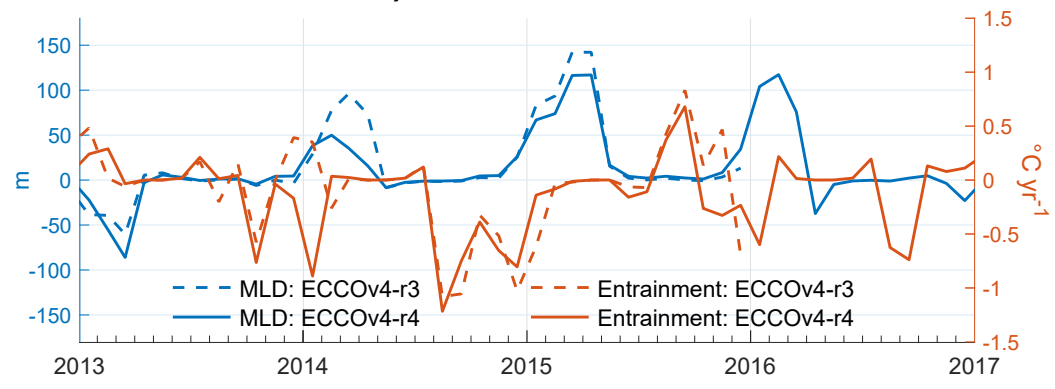

c) Temperature difference: mixed layer - thermocline

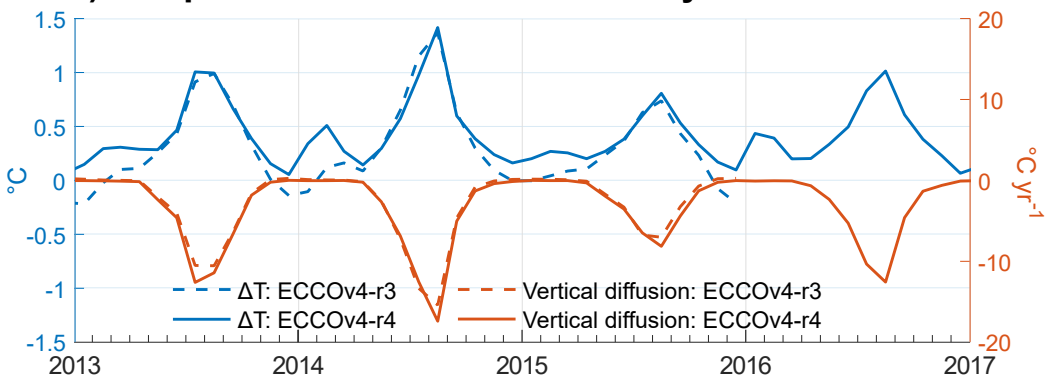

Figure 7. Time series of the individual components that comprise the dominant temperature budget terms, and the associated change in mixed layer temperature, both averaged over the cold blob region in ECCOv4-r4. a) Anomalies in the heat flux into the surface output by the model, defined as $Q_{n e t}$ in Equation 1 (W $\mathrm{m}^{-2}$; blue), and anomalies in the associated change in mixed layer temperature, i.e. the surface flux term of the mixed layer budget $\left({ }^{\circ} \mathrm{C} \mathrm{yr}^{-1}\right.$; red). b) Anomalies in MLD (m; blue) and the associated heat entrainment term of the mixed layer budget $\left({ }^{\circ} \mathrm{C} \mathrm{yr}^{-1}\right.$; red). c) The temperature difference between the mixed layer and the model cell immediately beneath $\left({ }^{\circ} \mathrm{C}\right.$; blue), defined as $\Delta T$ in Equation 1 where positive values signify that the mixed layer is warmer than the thermocline, and the associated vertical diffusion term of the mixed layer budget $\left({ }^{\circ}{\mathrm{C} \mathrm{yr}^{-1}}\right.$; red). Note, the seasonal cycle has not been removed from either term in $\left.\mathrm{c}\right)$.

of the mixed layer enhanced by entrainment during the autumn of 2014. The process of the re-emergence following the strong cooling of December 2013 is illustrated in Fig. 8. From June 2014 to January 2015, if the process of re-emergence is taken to 


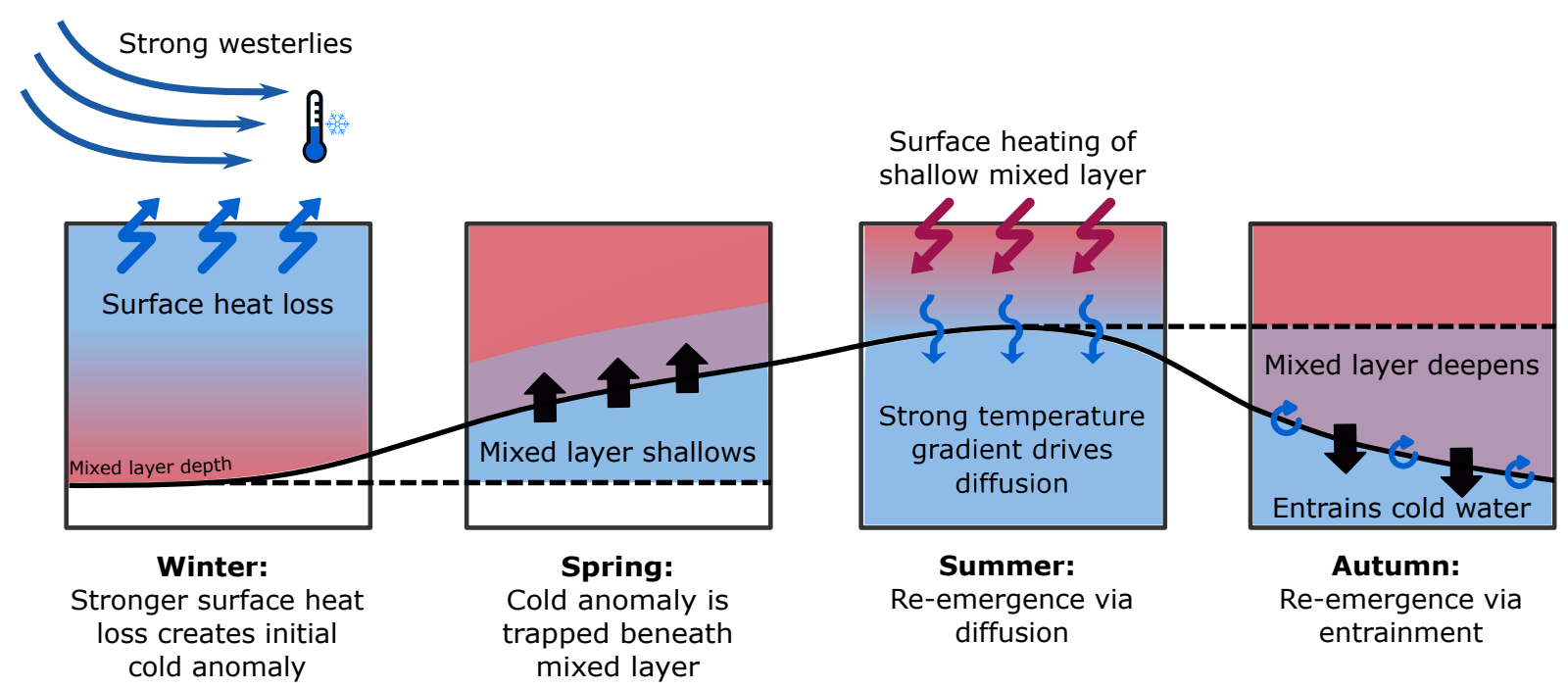

Figure 8. Schematic summarising the processes driving the re-emergence of the cold anomaly from beneath the mixed layer. The black arrows show the movement of the mixed layer and the red/blue arrows show the heat transfer. Initial surface heat loss drives a cold anomaly in the deep mixed layer during winter, which is sequestered as the mixed layer shallows the following spring/summer. During summer, surface heating of the shallow mixed layer generates a strong temperature gradient across the base of the mixed layer, resulting in strong diffusive cooling and driving the initial re-emergence of the cold anomaly. The mixed layer then deepens and cold water is entrained from beneath the mixed layer, driving further re-emergence.

be the sum of the cooling driven by vertical diffusion and entrainment, vertical diffusion is responsible for approximately $70 \%$ of the re-emergence, while entrainment is responsible for the remaining $30 \%$.

Anomalies in each term of the mixed layer budget over the winter of 2014/15 are small. Further negative anomalies in the surface forcing then occur in the summer of 2015, signifying surface heating that is around 10\% lower than the average from May to July 2015, and is exacerbated by the shallow summer mixed layer. Negative anomalies in the surface flux term occur from March to July 2015 in both models, reaching a minimum of $-0.5^{\circ} \mathrm{C}$ month ${ }^{-1}$ in each model during July. This then leads to the maximum cold anomaly in August 2015, within the shallow mixed layer.

Immediately after the peak of the anomaly, positive anomalies in the surface flux and diffusion terms cause a decline in the intensity of the cold anomaly. However, over the winter of 2015/16, anomalies in each term of the temperature budget are small, allowing for the diminished cold anomaly to continue through to 2016. In the summer of 2016, anomalously strong mixed layer warming via surface forcing erodes the cold anomaly, with the average mixed layer temperature anomaly in the region switching to positive in August 2016 in ECCOv4-r4.

\subsection{Spatial patterns in the 2015 cold anomaly}

Anomalies in the temperature budget terms in the lead up to the 2015 cold anomaly are not uniform across the subpolar North Atlantic, with the most extensive differences between the north and the south of the region. The budgets were therefore repeated 
a) Northern cold anomaly

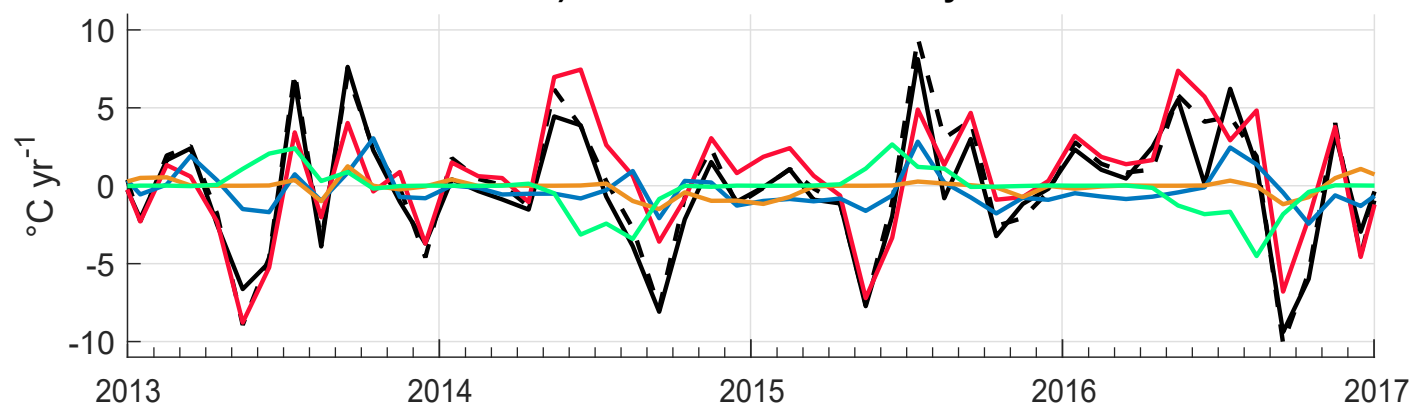

b) Southern cold anomaly

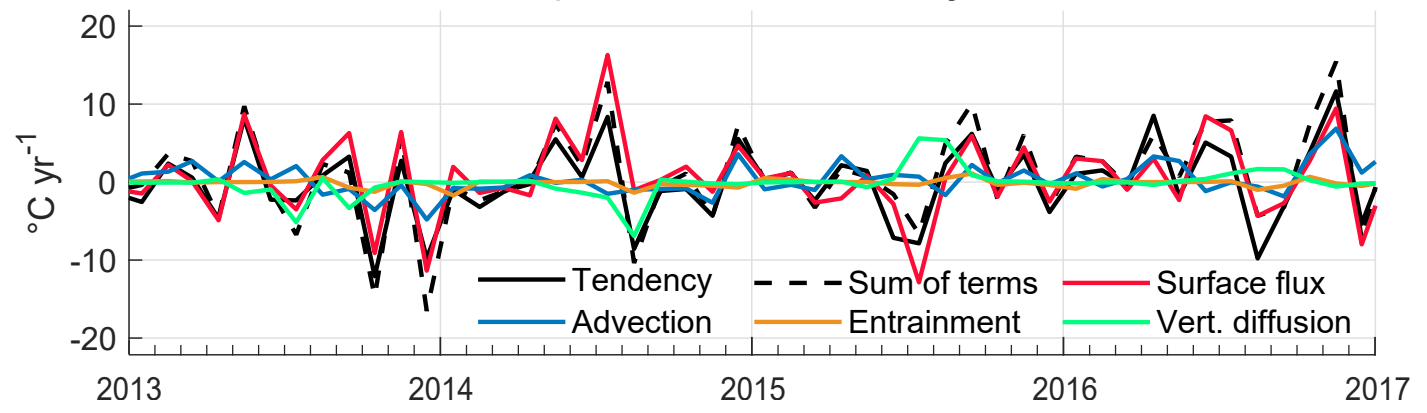

Figure 9. Anomalies in the mixed layer temperature budget $\left({ }^{\circ} \mathrm{C} \mathrm{yr}^{-1}\right)$ in ECCOv4-r4 as in Fig. 6b, but averaged over only a) the northern half of the cold blob region $\left(50-20^{\circ} \mathrm{W}, 53-63^{\circ} \mathrm{N}\right)$ and $\left.\mathrm{b}\right)$ the southern half of the cold anomaly $\left(50-20^{\circ} \mathrm{W}, 43-53^{\circ} \mathrm{N}\right)$. Note the different scales on the vertical axes.

and the anomalies averaged over the northern and southern halves of the cold blob region separately (Fig. 9; note the different scales on the vertical axes). Again, the components comprising the individual budget terms are also shown (Fig. 10), in order to further understand what causes the anomalies in the budget terms in each region. The results in this section are shown only for ECCOv4-r4, however very similar results for ECCOv4-r3 can be found in the Appendix (Fig. A2-A4). In general, the magnitude of the anomalies in the temperature budget terms is reduced in the north due to a meridional gradient in winter MLD, with deeper mixed layers in the north of the region.

The surface-driven cooling that drives the initial cold anomaly is much stronger in the south, with two clear peaks in October and December 2013 (Fig. 9b). The strongest surface-driven cooling of $-1.0^{\circ} \mathrm{C}$ month ${ }^{-1}$ occurs in December, compared to $-0.3^{\circ} \mathrm{C}$ month $^{-1}$ in the north. This is a result of the stronger surface ocean heat loss (Fig. 10a,b) and because the mixed layer is generally shallower in the south, so smaller anomalies in net heat flux are required to impact the average mixed layer temperature. A second earlier minimum in surface-driven cooling of the mixed layer is also clear in the south in October 2013, due to a a higher than average heat flux out of the surface ocean (Fig. 10b). In the north, $85 \%$ of the total cooling anomalies during December 2013 is a result of surface forcing, while the remaining 15\% is due to advection. In the south, the effect of 

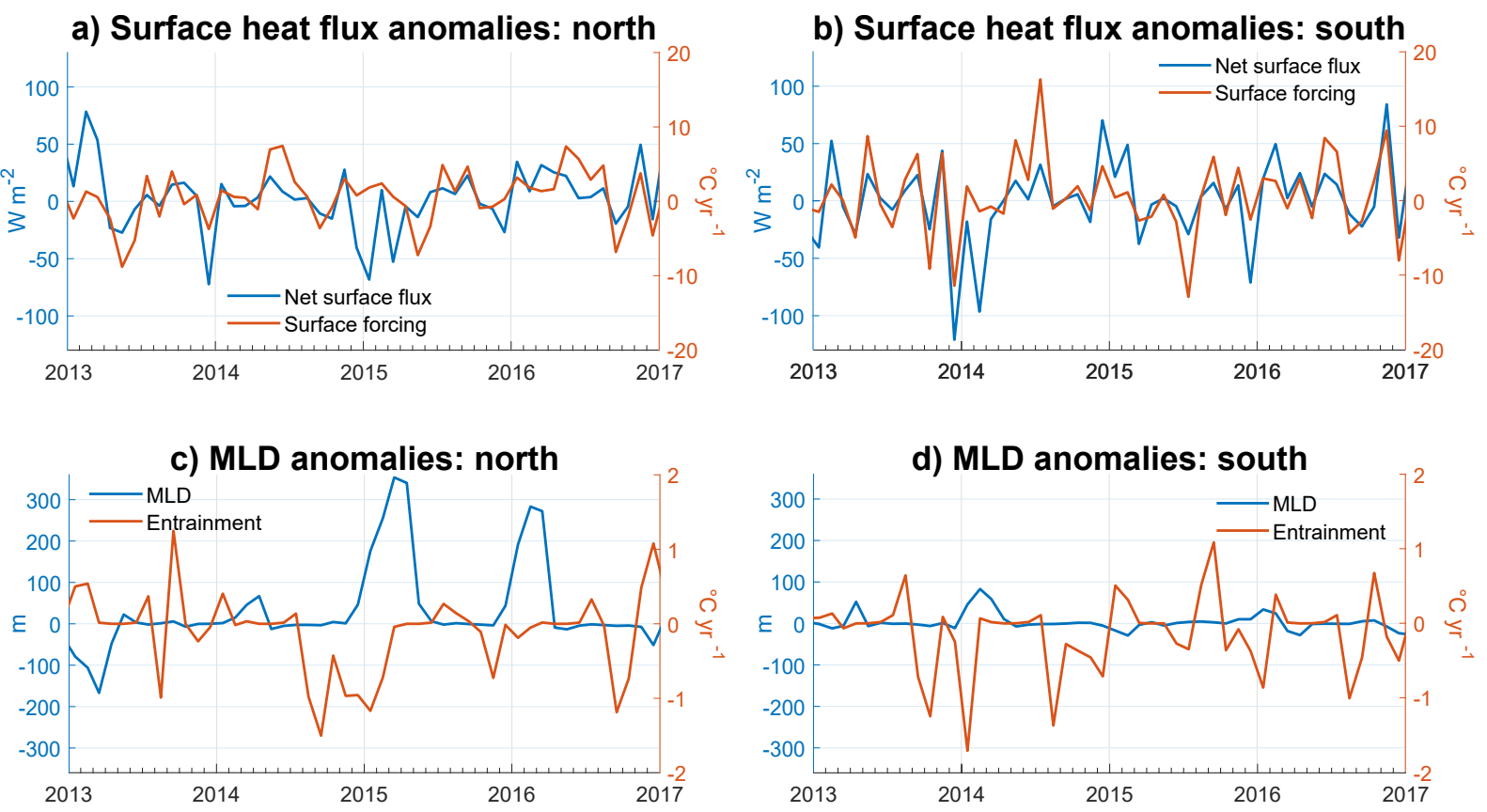

e) Temperature difference (mixed layer - thermocline): north
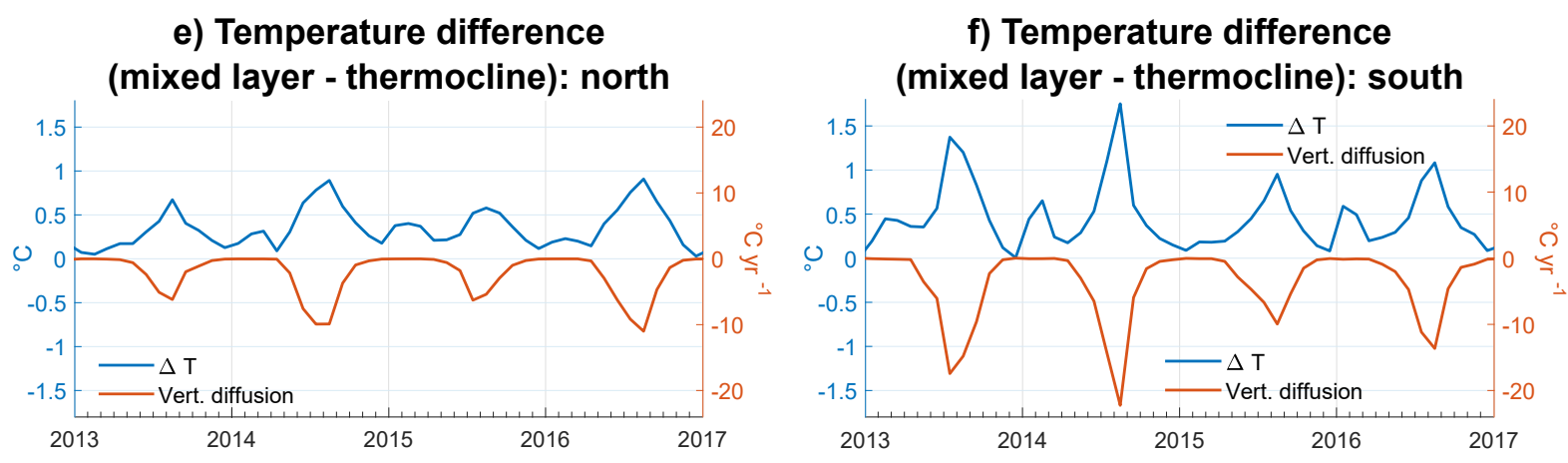

Figure 10. The individual components making up the dominant temperature budget terms and the associated change in mixed layer temperature, as in Fig. 7, but averaged only the northern (left panels) and the southern (right panels) halves of the cold blob region separately. a-d) show anomalies in the individual terms, while the seasonal cycle has not been removed for e-f).

advection is greater, driving approximately $30 \%$ of the initial cooling anomalies in December 2013, while the remaining $70 \%$ is due to surface forcing.

In the summer of 2014, the surface-driven warming is stronger in the south, but leads to a much greater temperature gradient across the base of the mixed layer than in the north (Fig. 10e,f), and subsequent stronger diffusive cooling of the mixed layer. The maximum diffusion in the south occurs in August 2014, reaching $-0.6^{\circ} \mathrm{C}$ month ${ }^{-1}$, while the maximum in the north reaches only $-0.3^{\circ} \mathrm{C} \mathrm{month}^{-1}$. This diffusive cooling is followed by stronger negative tendency anomalies in the north in September 2014, caused by a combination of surface fluxes, advection, entrainment and diffusion (Fig. 9a). The most negative anomalies 
https://doi.org/10.5194/os-2022-10

Preprint. Discussion started: 14 February 2022

are in the surface flux term, reaching $-0.3^{\circ} \mathrm{C}$ month ${ }^{-1}$, and are caused by negative anomalies in the heat flux into the ocean, which are not seen in the south (Fig. 10a,b). Anomalies in entrainment at this time are due to the continued strong temperature gradient across the base of the mixed layer, rather than anomalies in the MLD (Fig. 10e). Despite the anomalies generally being of a lower magnitude in the north, the strongest entrainment is a similar level to that in the south (Fig. 9), meaning that entrainment plays a greater role in the re-emergence of the cold anomaly in the north. Entrainment drives a mixed layer cooling also of $-0.1^{\circ} \mathrm{C}$ month ${ }^{-1}$ in August 2014 in the south, before driving a further cooling of $-0.1^{\circ} \mathrm{C} \mathrm{month}-1$ a month later in the north. While the temperature gradient at the mixed layer base is weaker in the north, anomalies in the MLD are much larger (Fig. 10c,d), leading to entrainment of a similar magnitude in both regions. In the north, anomalies in processes driving re-emergence from June 2014 to February 2015 are approximately $60 \%$ a result of vertical diffusion, and 40\% entrainment. In the south, where the impact of entrainment is lesser, the re-emergence over this period is a result of approximately $80 \%$ vertical diffusion and $20 \%$ entrainment.

In January 2015, strong surface heat loss in the north of the cold blob region (Fig. 10a) is not replicated in the surface flux term of the mixed layer budget, due to concurrent large anomalies in MLD. While surface forcing still drives a cooling of the mixed layer in January 2015, anomalies in the term are slightly positive as greater surface heat loss would be required to affect the temperature tendency of the greater volume of water in the mixed layer. The weakened surface-driven warming (negative anomalies) in the summer of 2015 leads in the north with a peak of $-0.6^{\circ} \mathrm{C}$ month ${ }^{-1}$ in May, followed by a peak in the south of $-1.0^{\circ} \mathrm{C}$ month $^{-1}$ in July (Fig. 9). In both cases, the negative anomalies are due to weak negative anomalies in the net heat flux (Fig. 10a,b) into a shallow summer mixed layer. In both the north and the south, the anomalies lead to the strongest SST anomalies in the summer of 2015 (Fig. 11). Anomalies in the surface warming of the mixed layer are positive from January to July 2016 in the north of the cold blob region, acting to diminish the cold anomaly. Positive anomalies in the surface flux term in the south also reach a similar magnitude, but oscillate between positive and negative. The processes driving the cold anomaly in the north and south of the cold blob region are illustrated in Fig. 11.

\subsection{Drivers of the surface-driven cooling of the mixed layer}

While multiple processes are important for the evolution of the 2015 cold anomaly, the anomaly would not have developed without the initial strong surface cooling in December 2013. Since there are clear differences in the magnitude of the heat flux out of the ocean in the north and south of the cold blob region during this period (Fig. 10a,b), the spatial distribution of anomalies in that heat flux is shown in Fig. 12a. To further understand the reasons for those spatial patterns, the simultaneous anomalies in the zonal and meridional components of the surface wind stress are also shown (Fig. 12c,e) as well as the anomalies in MLD (Fig. 12g).

While the negative anomalies in the surface heat flux extend across the majority of the subpolar North Atlantic in December 2013, the most negative anomalies occur in the cold blob region south of $54^{\circ} \mathrm{N}$, and to the northwest in the Labrador Sea (Fig. 12a). Averaged over the entire cold blob region, the heat flux out of the surface in December 2013 is approximately $45 \%$ greater than the climatological mean. At the same time, the usual westerly winds over the subpolar gyre are much stronger in the southern half of the North Atlantic and in the Labrador Sea (Fig. 12c), matching the patterns of negative anomalies in the 


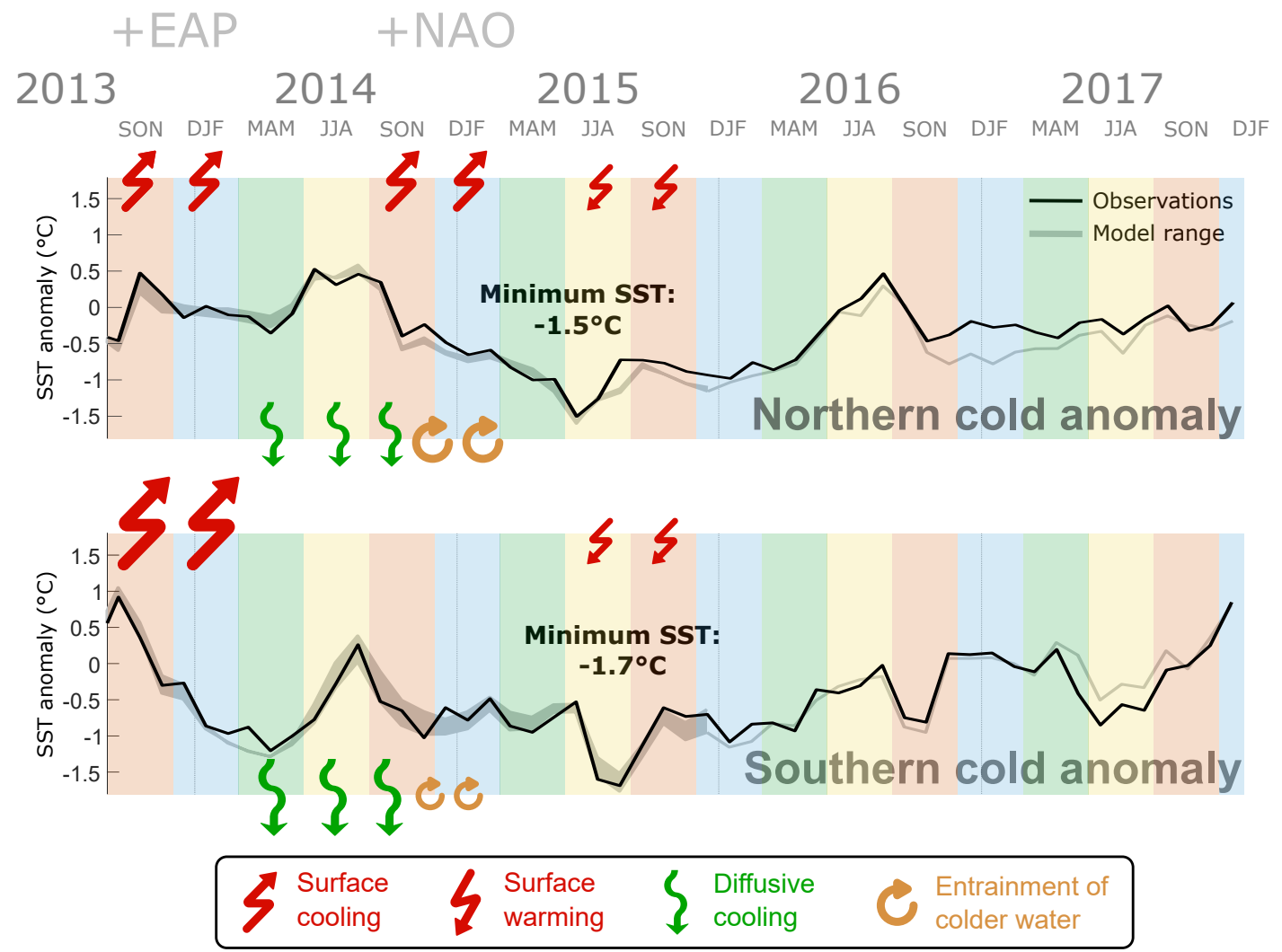

Figure 11. Schematic illustrating the processes involved in the evolution of the 2015 north Atlantic cold anomaly. The black line shows the SST anomaly in the HadISST1 observations averaged over the northern (top) and southern (bottom) halves of the cold blob region, with the 1992-2017 climatology removed, while the shading shows the range of the anomalies across both state estimates, averaged over the same region. The arrows show anomalies in the various processes driving the cold anomaly, with bigger arrows representing bigger anomalies.

surface heat flux. The westerly winds in December 2013 are approximately twice as strong as the average December zonal wind stress when averaged over the cold blob region. The only area of the cold blob region that does not experience anomalously strong westerly winds in December 2013 is in the far north, in the Irminger Sea. This is also the only region that experiences strong northerly wind anomalies (Fig. 12e) and positive anomalies in the net heat flux in December 2013, indicating lower than average heat loss. Anomalies in meridional wind stress are minimal across the rest of the region. These complementary patterns in surface heat flux and wind stress anomalies suggest that the initial development of the cold anomaly is the result of anomalous local winds, either increasing air-sea heat exchange due to the increased wind speed, or via the transport of cooler air over the region. This then leads to the anomalously strong surface cooling of the mixed layer that causes the initial development of the 2015 cold anomaly.

Strong surface forcing in the winter of 2014/15 has also previously been observed, linked to the positive state of the NAO (Yeager et al., 2016; Josey et al., 2018). However this was not seen in the anomalies of the mixed layer temperature budget, in 
a) Net surface heat flux

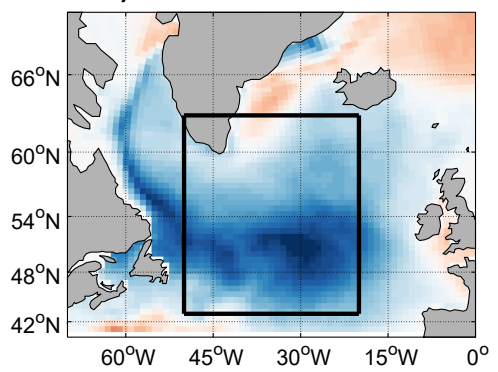

c) Zonal wind stress

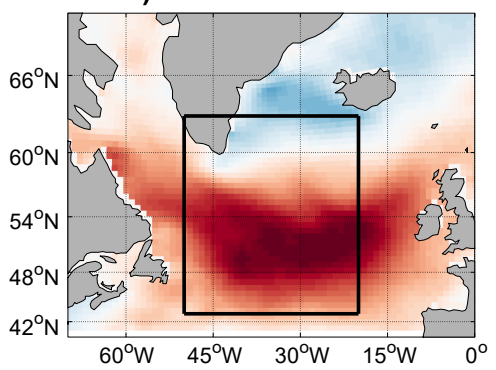

e) Meridional wind stress

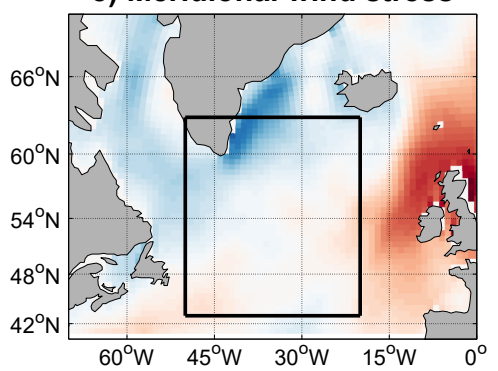

g) Mixed layer depth

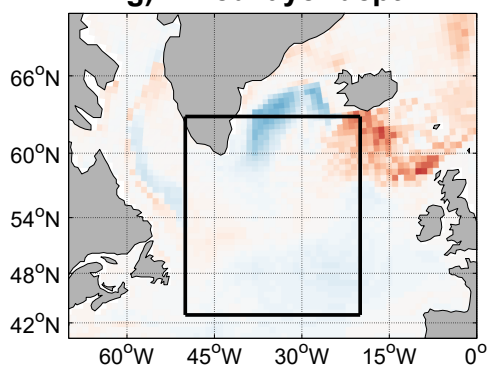

b) Net surface heat flux

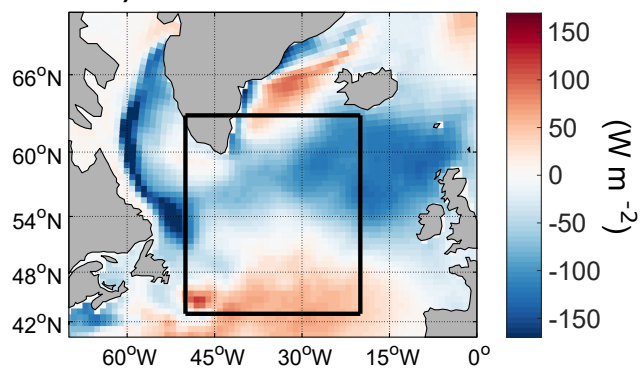

d) Zonal wind stress
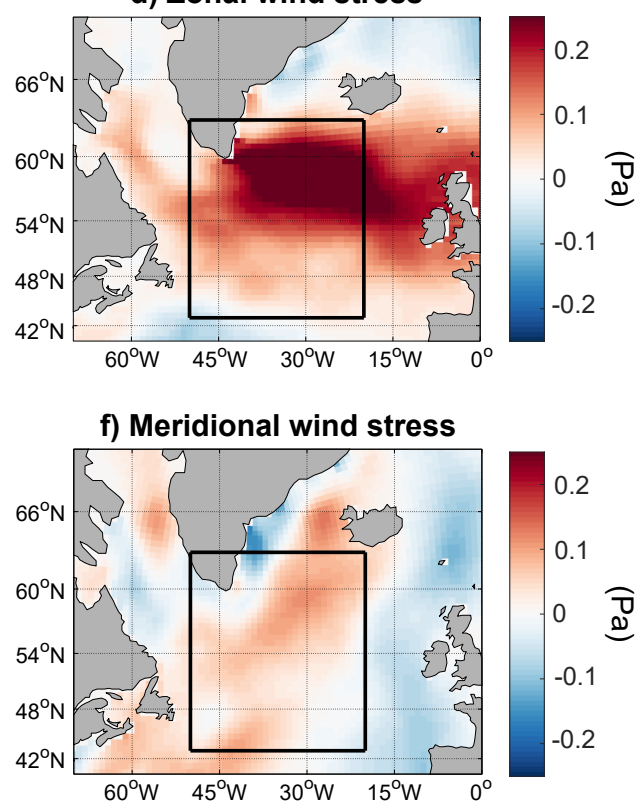

h) Mixed layer depth

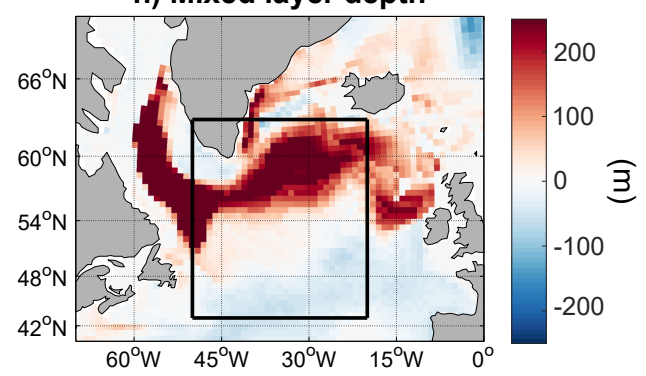

Figure 12. The spatial distribution of ECCOv4-r4 anomalies in the terms causing the initial anomalous surface cooling in December 2013 (left) and the same anomalies for January 2015 (right), when the net heat flux out of the surface was also high but its impact not seen in the temperature of the mixed layer. Shown are anomalies in a,b) the net surface heat flux $\left.\left(\mathrm{W} \mathrm{m}^{-2}\right), \mathrm{c}, \mathrm{d}\right)$ zonal wind stress $\left(\mathrm{m} \mathrm{s}{ }^{-1}\right)$, e,f) meridional wind stress $\left(\mathrm{m} \mathrm{s}^{-1}\right)$, and $\operatorname{MLD}(\mathrm{m})$. 
https://doi.org/10.5194/os-2022-10

Preprint. Discussion started: 14 February 2022

either the north or the south of the cold blob region (Fig. 9). Strong negative anomalies in the net surface flux into the ocean were present in January 2015 and the spatial distribution of these anomalies is shown in Fig. 12b. There are clear negative anomalies in the north which have a similar spatial pattern to positive anomalies in the zonal wind stress (Fig. 12d). At the same time, anomalies in the meridional wind stress are slightly positive across the majority of the cold blob region (Fig. 12f). Anomalies in the MLD in January 2015 (Fig. 12h) explain why the increased surface heat loss does not result in negative anomalies in the mixed layer temperature: the mixed layer is anomalously deep in the north of the cold blob region, so stronger surface forcing is required to affect the average temperature of the larger volume of water in the mixed layer. Therefore, while the mixed layer is cooling during January 2015, that cooling is no greater than the climatological average. Since the strong surface forcing extends to the east of the box defining the cold blob region (Fig. 12a,b), the mixed layer budget was repeated for a northeastern box $\left(35-5^{\circ} \mathrm{W}, 53-63^{\circ} \mathrm{N}\right.$; see Fig. A5). However, this did had little effect on the results and the anomalies in the surface flux term of the mixed layer budget were close to zero. While anomalies in the surface heat loss were indeed greater for this region, anomalies in MLD were still large enough to mask the effect on the temperature tendency of the mixed layer.

\section{Discussion}

\subsection{The influence of climate modes on the 2015 cold anomaly}

Previous studies have highlighted the influence of two climate modes of variability, namely the NAO and the EAP, on the development of the 2015 cold anomaly (Yeager et al., 2016; Josey et al., 2018; Maroon et al., 2021). During the initial cooling in the winter of 2013/14, the EAP was the dominant climate mode in the region and at its most positive state in at least six decades (Josey et al., 2018). The patterns in wind stress in December 2013 match composites of wind speeds for winters with a positive EAP index (Josey et al., 2019), with strong westerlies across the south of the region driving the anomalously strong heat flux out of the surface ocean. The anomalous northerly winds in the Irminger Sea during the same period also relate to the pattern of the positive EAP. This region has previously been shown to experience lower air-sea temperature and humidity gradients generated by northerly winds when the EAP index is positive (Josey et al., 2019), explaining the slightly increased surface heat loss, seen in December 2013.

During the following winter of 2014/15, the NAO was the dominant climate mode and anomalously positive. During a positive NAO event, stronger surface cooling is generally observed in the North Atlantic north of $45^{\circ}$, with weaker surface cooling in the south (Marshall et al., 2001). Positive NAO conditions have previously been shown to result in a particularly strong increase in the westerly winds in the Irminger Sea due to the interaction between the large scale flow and the Greenland topography (Doyle and Shapiro, 1999; Moore, 2003), as seen in the spatial distribution of zonal wind stress anomalies in January 2015. These strong westerly winds have been linked to increased surface heat loss in the north of the cold blob region (Josey et al., 2019). While the surface heat flux out of the ocean was stronger in the north during January 2015 when the the NAO was positive, this was not reflected in the anomalies of the mixed layer temperature; the effect was masked by anomalously deep mixed layers for the simple reason that larger volumes of water do not cool as readily as smaller volumes of water. When a more northeasterly region was considered, where surface heat loss in the winter of 2014/15 was more intense, 
https://doi.org/10.5194/os-2022-10

Preprint. Discussion started: 14 February 2022

the anomalies in MLD are still great enough to largely mask the effect on the anomalies in the surface flux term of the mixed layer budget. These results suggest that while the NAO clearly drove strong anomalies in winds and surface heat loss over the subpolar North Atlantic during the 2015 cold anomaly, the anomalously strong EAP appears to have had the largest effect on the temperature of the mixed layer as a whole.

\subsection{The re-emergence of the cold anomaly}

After appearing in late 2014, the cold SST anomaly was sustained through to 2015 via the re-emergence of the cold subsurface anomaly from below the mixed layer in the summer/autumn of 2015. Previous studies have linked the re-emergence of temperature anomalies in the North Atlantic to the deepening of the winter mixed layer (Cassou et al., 2007; Taws et al., 2011). While the deepening mixed layer did result in the entrainment of colder water from below, we found that this entrainment of colder water was not enough to explain the re-emergence of the cold SST anomaly. Instead, vertical diffusion dominated, while entrainment was still important but had a weaker influence. The re-emergence, via anomalies in both vertical diffusion and entrainment, appears to have been largely a result of the strong temperature gradient across the base of the mixed layer, which was particularly high in the summer/autumn of 2014 due to summer surface warming. The relative importance of entrainment was greater in the north of the cold blob region, where deeper winter mixed layers resulted in larger entrainment velocities in the autumn, though it was still a secondary process in comparison to the influence of vertical diffusion.

Since the mixed layer budgets were approximated and the diffusivity values chosen in order to reduce the error in the budgets, there is some error in the magnitude of the vertical diffusion term. However, the closed mixed layer temperature budget shows similar levels of diffusive cooling during the summer/autumn of 2014 (Fig. A1), giving further confidence in our results. Our chosen method of computing the budgets allows us to directly relate the levels of entrainment and vertical diffusion to changes in MLD and temperature, in order to describe the process of the re-emergence of the cold anomaly in greater detail.

\subsection{The influence of advection on the cold anomaly}

While previous studies have shown the importance of advection in driving variability in the upper ocean heat content of the North Atlantic (Buckley et al., 2014, 2015), they are not directly comparable with ours as they adopted a climatological monthly depth for the upper ocean rather than considering interannual variability in MLD. We found that the effect of advection on the temperature of the cold blob region as a whole was small both on seasonal and interannual timescales relative to the effect of surface forcing during the cold anomaly event. The results of the mixed layer budgets averaged over the entire cold blob region only show the net impact of advection transporting heat in and out of the region and not the redistribution of heat within it. However, when the northern and southern halves of the cold blob region were considered separately, advection still played only a small role in the initial cooling in comparison to surface forcing. The fact that the cold anomaly continued to cool while sequestered beneath the mixed layer in the spring/summer of 2014 and 2015 suggests that advection beneath the mixed layer was important for increasing the magnitude of the anomaly. This cooling below the mixed layer then acted to further increase the temperature gradient across the base of the mixed layer, enhancing the cooling of the mixed layer via vertical diffusion. 
https://doi.org/10.5194/os-2022-10

Preprint. Discussion started: 14 February 2022

Since advection played a minor role in comparison to surface forcing in driving the cooling that caused the cold anomaly to develop, particularly in the south of the region, we can conclude that the 2015 cold anomaly was largely the result of vertical processes, i.e. surface forcing, vertical diffusion, and entrainment. The dynamics of the 2015 cold anomaly could therefore likely be represented by a one-dimensional model, albeit with a slightly underestimated magnitude.

\subsection{Increased convection during the cold anomaly}

During the 2015 cold anomaly, the depth of the winter mixed layer in the cold blob region increased, reaching a maximum depth during the winter/spring of 2015. At the same time, the mixed layer in the region was undergoing a longer term freshening (Holliday et al., 2020), which is also present in the ECCOv4 state estimates (Fig. 13). The freshening indicates that the interannual deepening of the winter mixed layer was the result of stronger temperature-driven convection, while changes in salinity instead acted to stratify the mixed layer. The subsequent increased production of Subpolar Mode Water following the enhanced convection has also been suggested to have exacerbated the freshening via its impact on the velocity of the North Atlantic Current (Holliday et al., 2020). The timing of the fresh anomalies in ECCOv4 support this theory, with the strongest fresh anomalies occurring in the aftermath of the peak cold anomaly and the enhanced convection.

Average winter mixed layers are deeper in the north of the North Atlantic in comparison to further south. The MLD anomalies relative to the climatology were also much deeper in the north of the cold blob region over the evolution of the cold anomaly. MLDs were especially deep in the winter of 2015, explaining the stronger influence of entrainment in the north. The increased convection also had subsequent effects on the other terms of the temperature budget, with the differences in the depth of the mixed layers between the northern and southern regions leading to differences in how the mixed layer was impacted by anomalies in the overlying atmospheric conditions. This shows the importance of considering the spatial patterns in the drivers of this and similar cold anomalies in the North Atlantic, particularly the meridional differences in forcing.

\subsection{Mixed layer budgets in ECCO}

Following the methods of previous studies (Frankignoul, 1985; Peter et al., 2006; Dong et al., 2007), we chose to approximate

the mixed layer temperature budgets using monthly mean values, as opposed to values from each model timestep. Because our chosen method uses a certain set of well-understood assumptions, including the concepts of entrainment and lateral induction, it provides unique insights into the evolution of the mixed layer that would be unclear or unavailable in a closed-budget representation. This may sound counter-intuitive, since closed budgets are desirable in a large number of applications. The advantage comes from the fact that entrainment and lateral induction represent the average effect of how the temporally-varying mixed layer interacts with its environment over a chosen time period, in our case one month, in a way that is not captured by following the mixed layer at each timestep. The view of the mixed layer produced by this method should be considered as one among many, as different views will complement each other and help us build a more complete understanding of mixed layer evolution. That being said, for validation purposes, we did compare the similarities between the anomalies in our mixed layer budgets and those in the fully closed budgets, and we found them to be similar (See Appendix). 
a) ECCOv4-r3

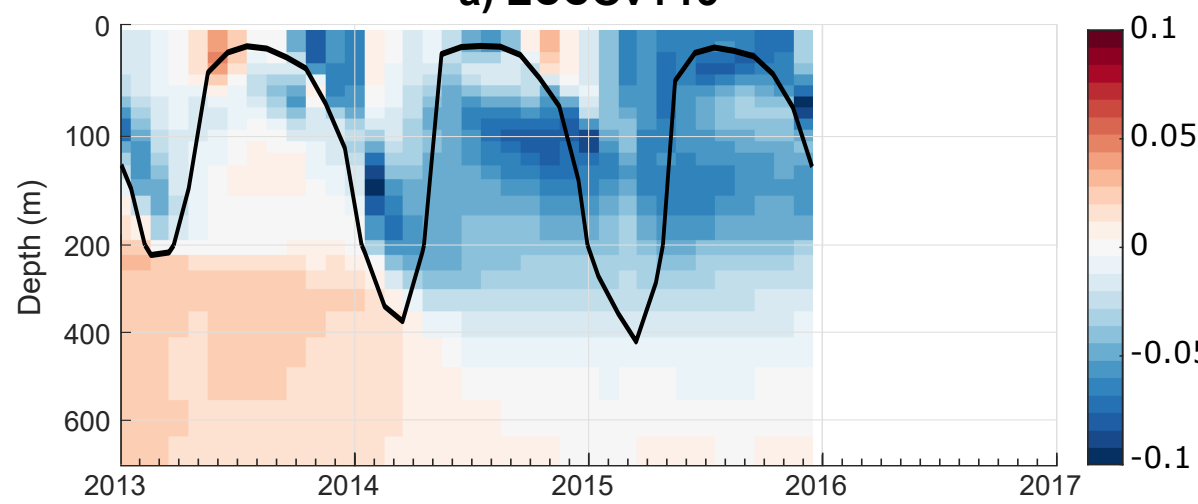

b) ECCOv4-r4

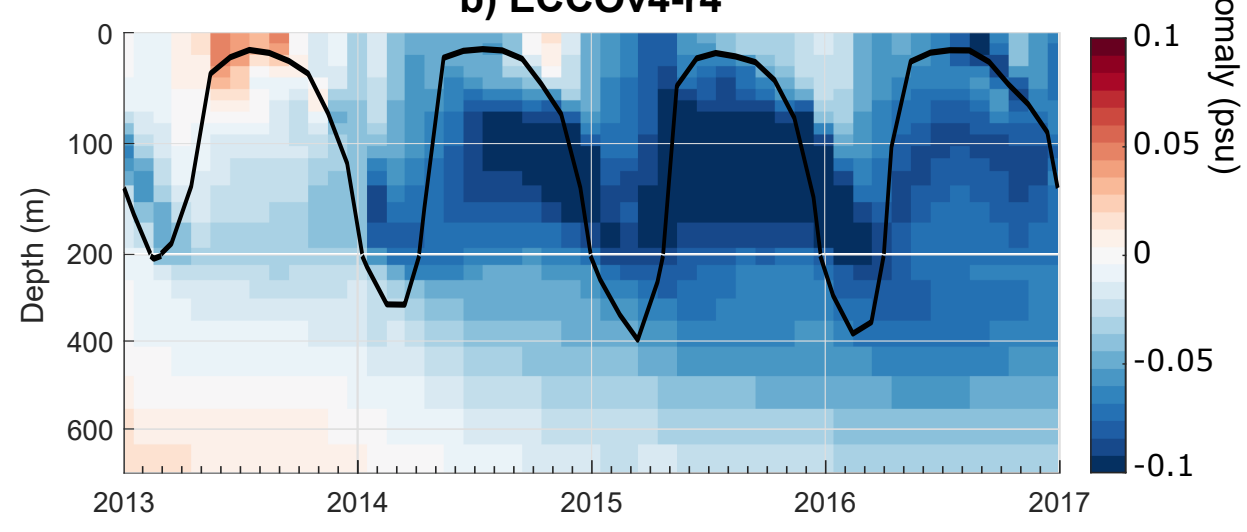

Figure 13. Salinity anomalies over depth relative to the 1992-2015 monthly climatology (color; psu), averaged over the cold blob region in a) ECCOv4-r3 and b) ECCOv4-r4 for the period leading up to and during the 2015 cold anomaly. The MLD is also shown (black line, m). Note the non-uniform spacing of the vertical axes.

The two ECCOv4 state estimates used here are relatively coarse in terms of their horizontal resolution. Unresolved processes are represented by mixing and bolus transport schemes whose parameters have been optimized by the 4D-VAR process, partially offsetting the limitations of the coarse model resolution. In particular, (Forget et al., 2015b, Fig. 4) showed that optimizing the spatially-varying mixing coefficients in ECCOv4 greatly improved the representation of its water mass properties.

\section{Conclusions}

In this work, we used the ECCOv4 state estimate to analyze the causes of the 2015 North Atlantic cold anomaly. The anomaly was primarily driven by strong surface forcing; specifically, anomalous winds were responsible for the majority of the initial cooling in the winter of 2013/14. This cooling was strongest in the south of the anomaly region, related to the strongly positive EAP. The re-emergence of the cold anomaly the following winter was primarily driven by vertical diffusion due to a strong temperature gradient across the base of the mixed layer, while entrainment over the same period was relatively weak. Although 
https://doi.org/10.5194/os-2022-10

Preprint. Discussion started: 14 February 2022

(C) Author(s) 2022. CC BY 4.0 License.

430 the NAO was strongly positive in the winter of 2014/15, the associated anomalous surface cooling in the north of the cold anomaly region was not reflected in the mixed layer temperature, as deeper winter mixed layers masked the impact of surface cooling on temperature. Advection played a minor role in the evolution of the cold anomaly, however more work on the processes occurring beneath the mixed layer would be useful for determining whether advection was the cause of the continued cooling of the sequestered cold anomaly. Further work investigating the cold anomaly in higher resolution models would also be a welcome addition to the literature.

Code and data availability. The ECCOv4-r3 data can be found at https://ecco.jpl.nasa.gov/drive/files/Version4/Release3 (downloaded June 2018), and the ECCOv4-r4 data can be found at https://ecco.jpl.nasa.gov/drive/files/Version4/Release4/ (downloaded January 2021) (ECCO Consortium et al., 2021). ECCO version 4 is described by Forget et al. (2015a), and ECCO version 4 releases 3 and 4 are described by Fukumori et al. (2017) and ECCO Consortium et al. (2021) respectively.

The HadISST observational data used to produce Fig. 1 can be found at https://www.metoffice.gov.uk/hadobs/hadisst/data/download.html, and is described by Rayner et al. (2003)

\section{Appendix A}

Acknowledgements. RS was supported by the UK Natural Environment Research Council ACSIS program: NE/N018028/1. DJ was supported by UK Research and Innovation grant: MR/T020822/1. The authors thank An T. Nguyen and Helen Pillar for their helpful discussion in the analysis of the mixed layer budgets. 
https://doi.org/10.5194/os-2022-10

Preprint. Discussion started: 14 February 2022

(c) Author(s) 2022. CC BY 4.0 License.

(c) (i)

a) Eccov4-r3

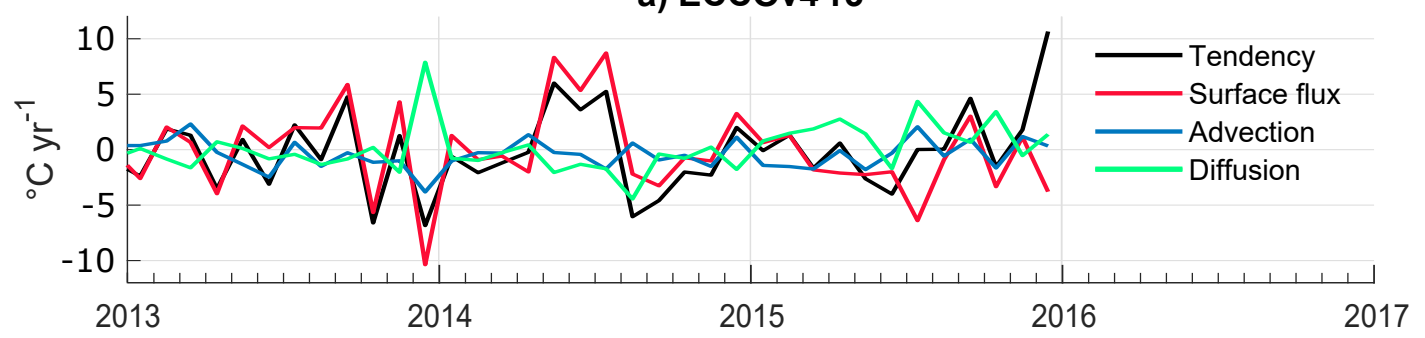

b) ECCOv4-r4

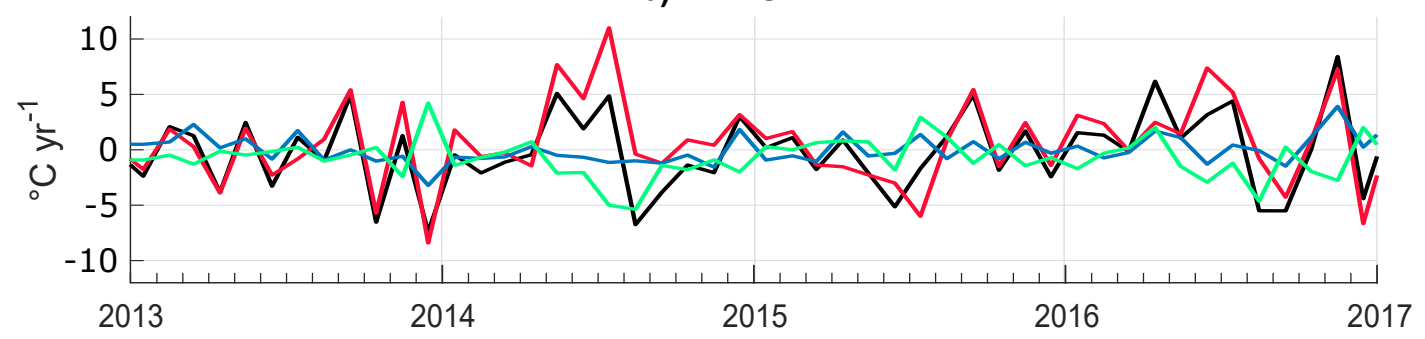

Figure A1. Anomalies in the closed mixed layer budgets $\left({ }^{\circ} \mathrm{C} \mathrm{yr}^{-1}\right)$ computed online in a) ECCOv4r3 and b) ECCOv4r4. Each term is computed within each individual model cell, then the results for the cells contained within the mixed layer at each timestep are averaged. The results are then averaged over the cold blob region. These budgets do not take into account the dynamic nature of the mixed layer and so do not include an entrainment term representing the changing depth over time.

\section{References}

Alexander, M. A., Deser, C., and Timlin, M. S.: The Reemergence of SST Anomalies in the North Pacific Ocean, Journal of Climate, 12, 2419-2433, https://doi.org/10.1175/1520-0442(1999)012<2419:TROSAI>2.0.CO;2, 1999.

Barnston, A. G. and Livezey, R. E.: Classification, seasonality and persistence of low-frequency atmospheric circulation patterns, Monthly weather review, 115, 1083-1126, https://doi.org/10.1175/1520-0493(1987)115<1083:CSAPOL>2.0.CO;2, 1987.

Buckley, M. W., Ponte, R. M., Forget, G., and Heimbach, P.: Low-frequency SST and upper-ocean heat content variability in the North Atlantic, Journal of Climate, 27, 4996-5018, https://doi.org/10.1175/JCLI-D-13-00316.1, 2014.

Buckley, M. W., Ponte, R. M., Forget, G., and Heimbach, P.: Determining the origins of advective heat transport convergence variability in the North Atlantic, Journal of Climate, 28, 3943-3956, https://doi.org/10.1175/JCLI-D-14-00579.1, 2015.

Cassou, C., Deser, C., and Alexander, M. A.: Investigating the impact of reemerging sea surface temperature anomalies on the winter atmospheric circulation over the North Atlantic, Journal of climate, 20, 3510-3526, https://doi.org/10.1175/JCLI4202.1, 2007.

Chakraborty, A. and Campin, J.-M.: Heat and salt budgets in MITgcm, Tech. rep., Atmospheric and Oceanic Sciences Group, Space Applications Centre, Indian Space Research Organization, Ahmedabad, India, 2013.

de Jong, M. F. and de Steur, L.: Strong winter cooling over the Irminger Sea in winter 2014-2015, exceptional deep convection, and the emergence of anomalously low SST, Geophysical Research Letters, 43, 7106-7113, https://doi.org/10.1002/2016GL069596, 2016.

Desbruyères, D. G., Mercier, H., Maze, G., and Daniault, N.: Surface predictor of overturning circulation and heat content change in the subpolar North Atlantic, Ocean Science, 15, 809-817, https://doi.org/10.5194/os-15-809-2019, 2019. 
https://doi.org/10.5194/os-2022-10

Preprint. Discussion started: 14 February 2022

(c) Author(s) 2022. CC BY 4.0 License.

(c)

a) Northern cold anomaly

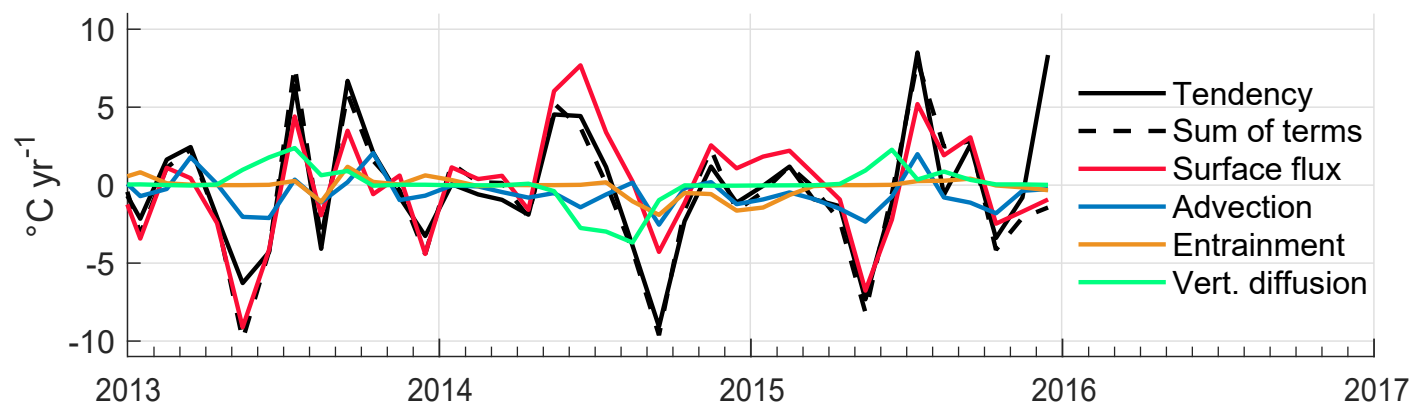

b) Southern cold anomaly

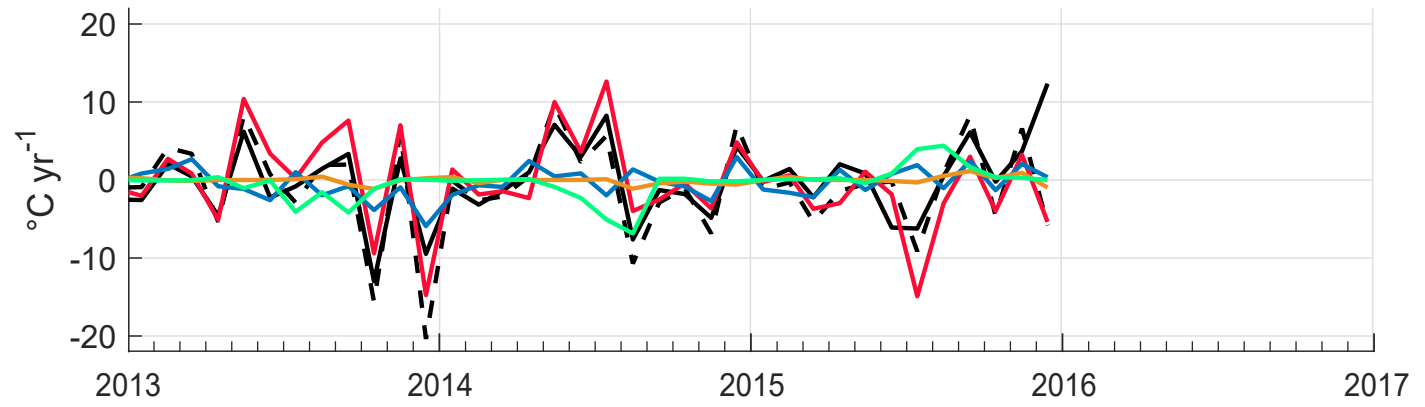

Figure A2. Anomalies in the dominant terms of the mixed layer temperature budget, relative to the $1992-2015$ monthly climatology $\left({ }^{\circ} \mathrm{C}\right.$ $\mathrm{yr}^{-1}$ ) for ECCOv4-r3. The anomalies in the model temperature tendency are shown by the solid black line, and the anomalies in the sum of the temperature budget terms driving the change in temperature by the dashed black line. The remaining lines represent those individual terms: the surface heat flux (red), horizontal advection (blue), vertical entrainment (orange), and vertical diffusion (green). The results are averaged over a) the northern half of the cold blob region $\left(50-20^{\circ} \mathrm{W}, 53-63^{\circ} \mathrm{N}\right)$ and $\left.\mathrm{b}\right)$ the southern half of the cold anomaly $\left(50-20^{\circ} \mathrm{W}\right.$, $\left.43-53^{\circ} \mathrm{N}\right)$.

Dong, S., Gille, S. T., and Sprintall, J.: An assessment of the Southern Ocean mixed layer heat budget, Journal of Climate, 20, 4425-4442, https://doi.org/10.1175/JCLI4259.1, 2007.

Doyle, J. D. and Shapiro, M. A.: Flow response to large-scale topography: The Greenland tip jet, Tellus A, 51, 728-748, https://doi.org/10.1034/j.1600-0870.1996.00014.x, 1999.

Drijfhout, S., Van Oldenborgh, G. J., and Cimatoribus, A.: Is a decline of AMOC causing the warming hole above the North Atlantic in observed and modeled warming patterns?, Journal of Climate, 25, 8373-8379, https://doi.org/10.1175/JCLI-D-12-00490.1, 2012.

Duchez, A., Frajka-Williams, E., Josey, S., Evans, D., Grist, J., Marsh, R., McCarthy, G., Sinha, B., Berry, D., and JJ-M, H.: Drivers of exceptionally cold North Atlantic Ocean temperatures and their link to the 2015 European heat wave, Environmental Research Letters, 11, https://doi.org/10.1088/1748-9326/11/7/074004, 2016.

ECCO Consortium, Fukumori, I., Wang, O., Fenty, I., Forget, G., Heimbach, P., and Ponte, R.: Synopsis of the ECCO central production global Ocean and sea-ice state estimate, version 4 release 4, https://doi.org/10.5281/zenodo.3765929, retrieved from, https://ecco.jpl.nasa. gov/drive/files/Version4/Release4, 2021. 
https://doi.org/10.5194/os-2022-10

Preprint. Discussion started: 14 February 2022

(c) Author(s) 2022. CC BY 4.0 License.

(c) (i)

Forget, G., Campin, J.-M., Heimbach, P., Hill, C. N., Ponte, R. M., and Wunsch, C.: ECCO version 4: An integrated framework for nonlinear inverse modeling and global ocean state estimation, Geoscientific Model Development, 8, 3071-3104, https://doi.org/10.5194/gmd8-3071-2015, 2015a.

Forget, G., Ferreira, D., and Liang, X.: On the observability of turbulent transport rates by Argo: supporting evidence from an inversion experiment, Ocean Science, 11, 839-853, https://doi.org/10.5194/os-11-839-2015, 2015b.

Frankignoul, C.: Sea surface temperature anomalies, planetary waves, and air-sea feedback in the middle latitudes, Reviews of geophysics, 23, 357-390, https://doi.org/10.1029/RG023i004p00357, 1985.

Fukumori, I., Wang, O., Fenty, I., Forget, G., Heimbach, P., and Ponte, R. M.: ECCO version 4 release 3, Tech. rep., https://dspace.mit.edu/ handle/1721.1/110380, 2017

Gaspar, P. and Gréegoris, Y.: A simple eddy-kinetic-energy model for simulations of the ocean vertical mixing: tests at station Papa and long-term upper ocean study site, Journal of Geophysical Research, 95, 16-179, https://doi.org/10.1029/JC095iC09p16179, 1990.

Gent, P. R. and Mcwilliams, J. C.: Isopycnal mixing in ocean circulation models, Journal of Physical Oceanography, 20, 150-155, https://doi.org/10.1175/1520-0485(1990)020<0150:IMIOCM>2.0.CO;2, 1990.

Grist, J. P., Josey, S. A., Jacobs, Z. L., Marsh, R., Sinha, B., and Van Sebille, E.: Extreme air-sea interaction over the North Atlantic subpolar gyre during the winter of 2013-2014 and its sub-surface legacy, Climate dynamics, 46, 4027-4045, https://doi.org/10.1007/s00382-0152819-3, 2016.

495 Hátún, H., Olsen, B., and Pacariz, S.: The dynamics of the North Atlantic subpolar gyre introduces predictability to the breeding success of kittiwakes, Frontiers in Marine Science, 4, 123, https://doi.org/10.3389/fmars.2017.00123, 2017.

Holliday, N. P., Bersch, M., Berx, B., Chafik, L., Cunningham, S., Florindo-López, C., Hátún, H., Johns, W., Josey, S. A., Larsen, K. M. H., et al.: Ocean circulation causes the largest freshening event for 120 years in eastern subpolar North Atlantic, Nature Communications, 11, 1-15, https://doi.org/10.1038/s41467-020-14474-y, 2020.

Josey, S., De Jong, M., Oltmanns, M., Moore, G., and Weller, R.: Extreme variability in Irminger Sea winter heat loss revealed by ocean observatories initiative mooring and the ERA5 reanalysis, Geophysical Research Letters, 46, 293-302, https://doi.org/10.1029/2018GL080956, 2019.

Josey, S. A., Hirschi, J. J.-M., Sinha, B., Duchez, A., Grist, J. P., and Marsh, R.: The recent Atlantic cold anomaly: Causes, consequences, and related phenomena, Annual review of marine science, 10, 475-501, https://doi.org/10.1146/annurev-marine-121916-063102, 2018.

Kostov, Y., Johnson, H. L., Marshall, D. P., Heimbach, P., Forget, G., Holliday, N. P., Lozier, M. S., Li, F., Pillar, H. R., and Smith, T.: Distinct sources of interannual subtropical and subpolar Atlantic overturning variability, Nature Geoscience, pp. 1-5, https://doi.org/10.1038/s41561-021-00759-4, 2021.

Lamb, P. J. and Peppler, R. A.: North Atlantic Oscillation: concept and an application, Bulletin of the American Meteorological Society, 68, 1218-1225, https://doi.org/10.1175/1520-0477(1987)068<1218:NAOCAA>2.0.CO;2, 1987.

510 Large, W. and Yeager, S.: The global climatology of an interannually varying air-sea flux data set, Climate dynamics, 33, 341-364, https://doi.org/10.1007/s00382-008-0441-3, 2009.

Losch, M., Menemenlis, D., Campin, J.-M., Heimbach, P., and Hill, C.: On the formulation of sea-ice models. Part 1: Effects of different solver implementations and parameterizations, Ocean Modelling, 33, 129-144, https://doi.org/10.1016/j.ocemod.2009.12.008, 2010.

Maroon, E. A., Yeager, S. G., Danabasoglu, G., and Rosenbloom, N.: Was the 2015 North Atlantic subpolar cold anomaly predictable?, Journal of Climate, pp. 1-69, https://doi.org/10.1175/JCLI-D-20-0750.1, 2021. 
https://doi.org/10.5194/os-2022-10

Preprint. Discussion started: 14 February 2022

(c) Author(s) 2022. CC BY 4.0 License.

(c) (i)

Marshall, J., Johnson, H., and Goodman, J.: A study of the interaction of the North Atlantic Oscillation with ocean circulation, Journal of Climate, 14, 1399-1421, https://doi.org/10.1175/1520-0442(2001)014<1399:ASOTIO>2.0.CO;2, 2001.

Mecking, J., Drijfhout, S., Hirschi, J. J., and Blaker, A.: Ocean and atmosphere influence on the 2015 European heatwave, Environmental Research Letters, 14, 114 035, https://doi.org/10.1088/1748-9326/ab4d33, 2019.

520 Moore, G.: Gale force winds over the Irminger Sea to the east of Cape Farewell, Greenland, Geophysical Research Letters, 30, https://doi.org/10.1029/2003GL018012, 2003.

Peter, A.-C., Le Hénaff, M., Du Penhoat, Y., Menkes, C. E., Marin, F., Vialard, J., Caniaux, G., and Lazar, A.: A model study of the seasonal mixed layer heat budget in the equatorial Atlantic, Journal of Geophysical Research: Oceans, 111, https://doi.org/10.1029/2005JC003157, 2006.

Piecuch, C. G.: A note on practical evaluation of budgets in ECCO version 4 release 3, Tech. rep., http://hdl.handle.net/1721.1/111094, 2017.

Piron, A., Thierry, V., Mercier, H., and Caniaux, G.: Gyre-scale deep convection in the subpolar North Atlantic Ocean during winter 20142015, Geophysical Research Letters, 44, 1439-1447, https://doi.org/10.1002/2016GL071895, 2017.

Rahmstorf, S., Box, J. E., Feulner, G., Mann, M. E., Robinson, A., Rutherford, S., and Schaffernicht, E. J.: Exceptional twentieth-century slowdown in Atlantic Ocean overturning circulation, Nature climate change, 5, 475-480, https://doi.org/10.1038/nclimate2554, 2015.

530 Rayner, N., Parker, D. E., Horton, E., Folland, C. K., Alexander, L. V., Rowell, D., Kent, E., and Kaplan, A.: Global analyses of sea surface temperature, sea ice, and night marine air temperature since the late nineteenth century, Journal of Geophysical Research: Atmospheres, 108, https://doi.org/10.1029/2002JD002670, 2003.

Rogers, J. C.: The association between the North Atlantic Oscillation and the Southern Oscillation in the northern hemisphere, Monthly Weather Review, 112, 1999-2015, https://doi.org/10.1175/1520-0493(1984)112<1999:TABTNA>2.0.CO;2, 1984.

Sutton, R. and Mathieu, P.-P.: Response of the atmosphere-ocean mixed-layer system to anomalous ocean heat-flux convergence, Quarterly Journal of the Royal Meteorological Society: A journal of the atmospheric sciences, applied meteorology and physical oceanography, 128, 1259-1275, https://doi.org/10.1256/003590002320373283, 2002.

Taws, S. L., Marsh, R., Wells, N. C., and Hirschi, J.: Re-emerging ocean temperature anomalies in late-2010 associated with a repeat negative NAO, Geophysical Research Letters, 38, https://doi.org/10.1029/2011GL048978, 2011.

540 Wallace, J. M. and Gutzler, D. S.: Teleconnections in the geopotential height field during the Northern Hemisphere winter, Monthly weather review, 109, 784-812, https://doi.org/10.1175/1520-0493(1981)109<0784:TITGHF>2.0.CO;2, 1981.

Yeager, S. G., Kim, W. M., and Robson, J.: What caused the Atlantic cold blob of 2015?, US CLIVAR Variations, 14, 24-31, 2016. 

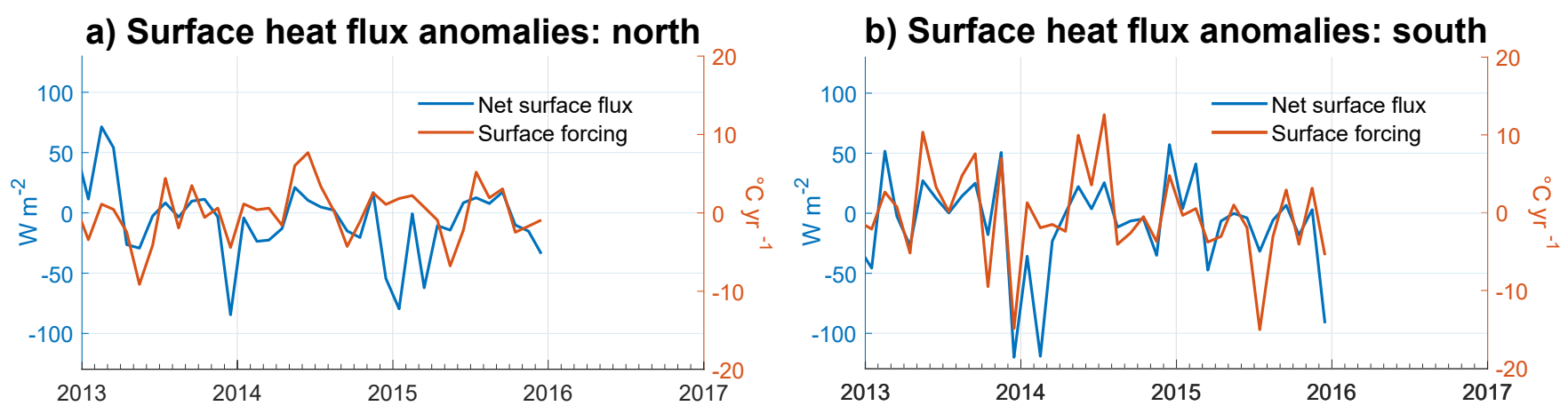

c) MLD anomalies: north

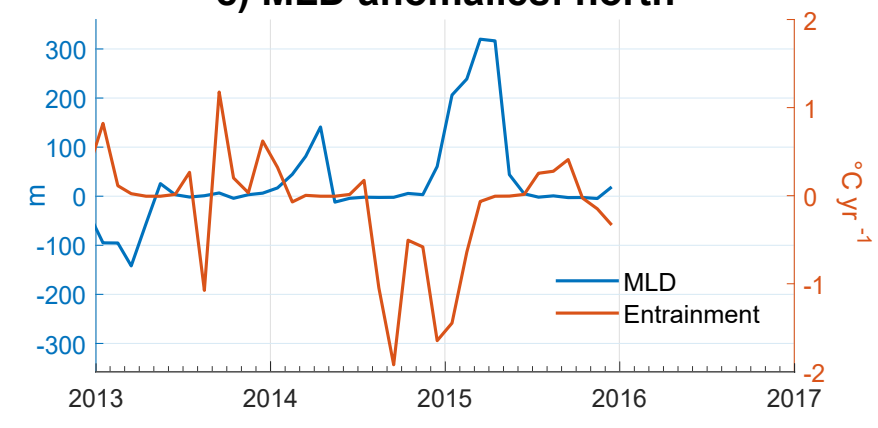

d) MLD anomalies: south

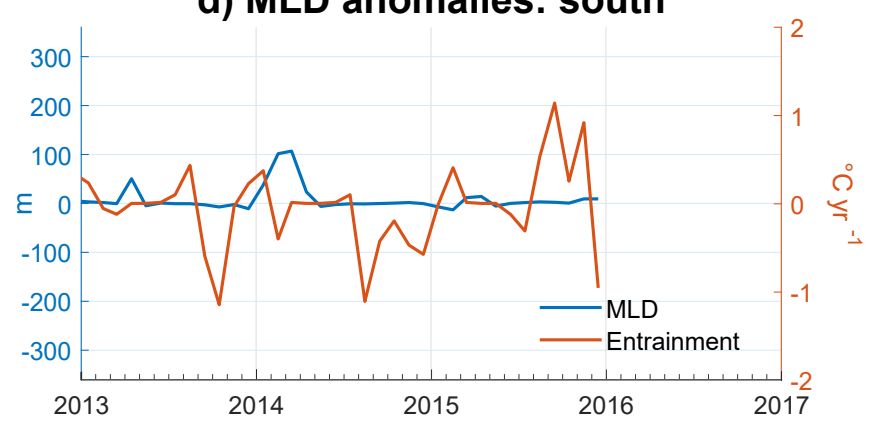

e) Temperature difference (mixed layer - thermocline): north
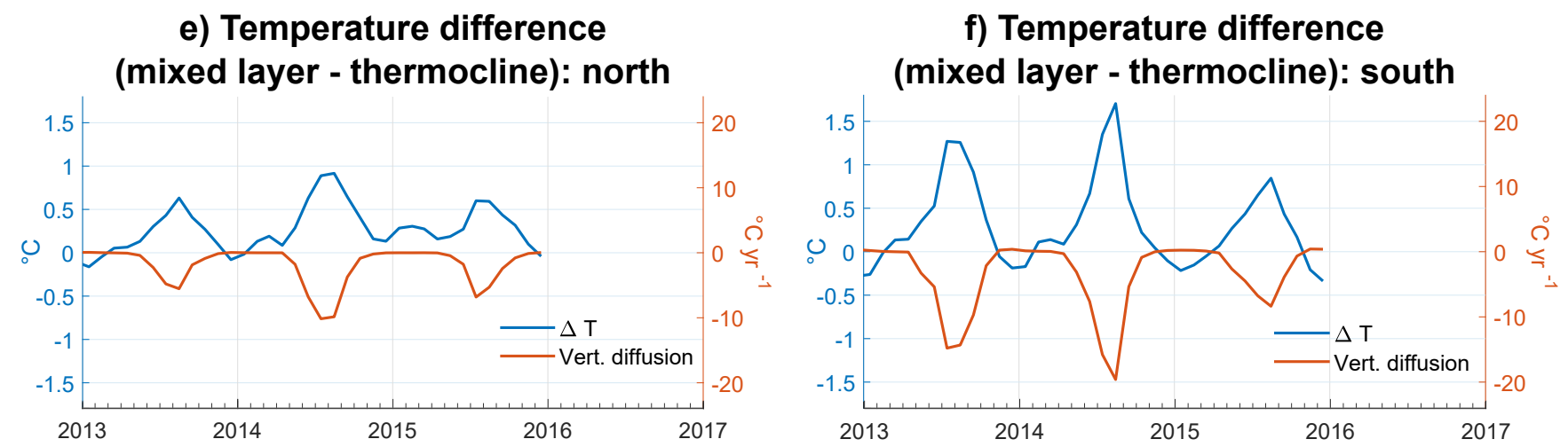

Figure A3. Time series of the individual components that comprise the dominant temperature budget terms, and the associated change in mixed layer temperature, both averaged over the north (left) and south (right) of the cold blob region in ECCOv4-r3. a) Anomalies in the heat flux into the surface output by the model, defined as $Q_{n e t}$ in Equation $1\left(\mathrm{~W} \mathrm{~m}^{-2}\right.$; blue), and anomalies in the associated change in mixed layer temperature, i.e. the surface flux term of the mixed layer budget $\left({ }^{\circ} \mathrm{C} \mathrm{yr}^{-1}\right.$; red). b) Anomalies in MLD (m; blue) and the associated heat entrainment term of the mixed layer budget $\left({ }^{\circ}{\mathrm{C} r^{-1}}\right.$; red). c) The temperature difference between the mixed layer and the model cell immediately beneath $\left({ }^{\circ} \mathrm{C}\right.$; blue), defined as $\Delta T$ in Equation 1 where positive values signify that the mixed layer is warmer than the thermocline, and the associated vertical diffusion term of the mixed layer budget $\left({ }^{\circ} \mathrm{C} \mathrm{yr}^{-1}\right.$; red). Note, the seasonal cycle has not been removed from either term in c). 
a) Net surface heat flux

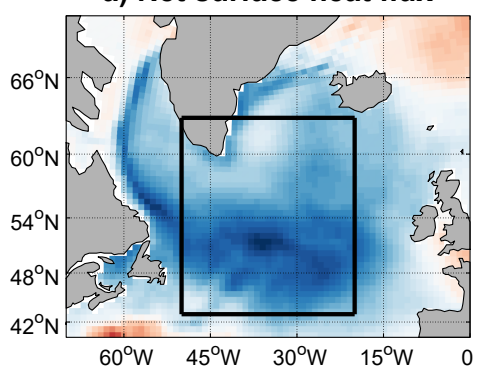

b) Zonal wind stress

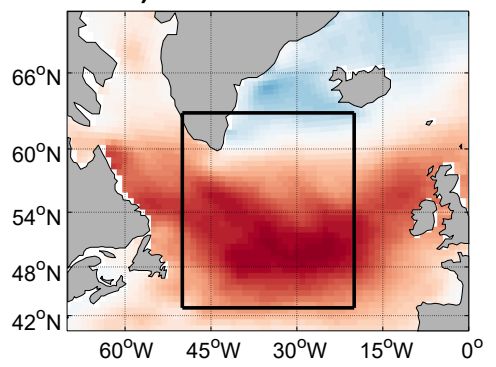

c) Meridional wind stress

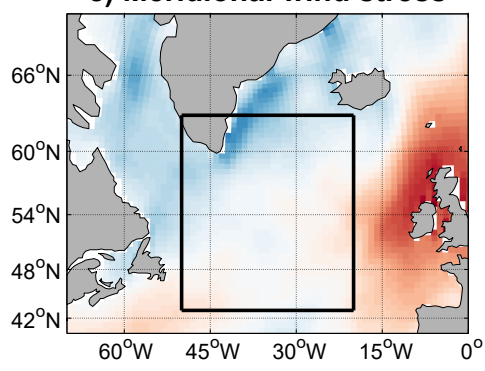

g) Mixed layer depth

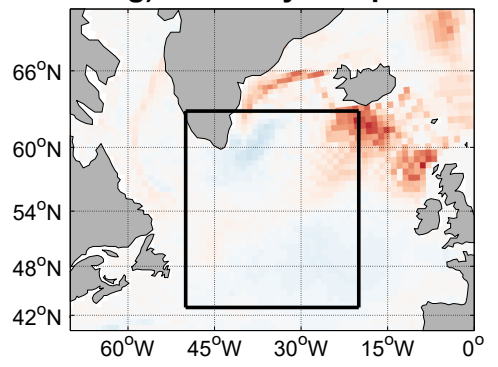

\section{b) Net surface heat flux}

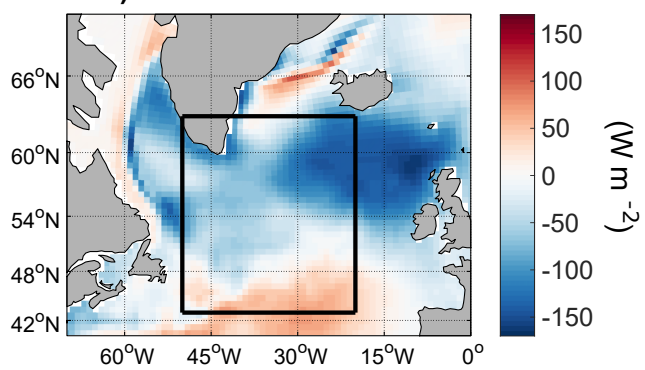

d) Zonal wind stress
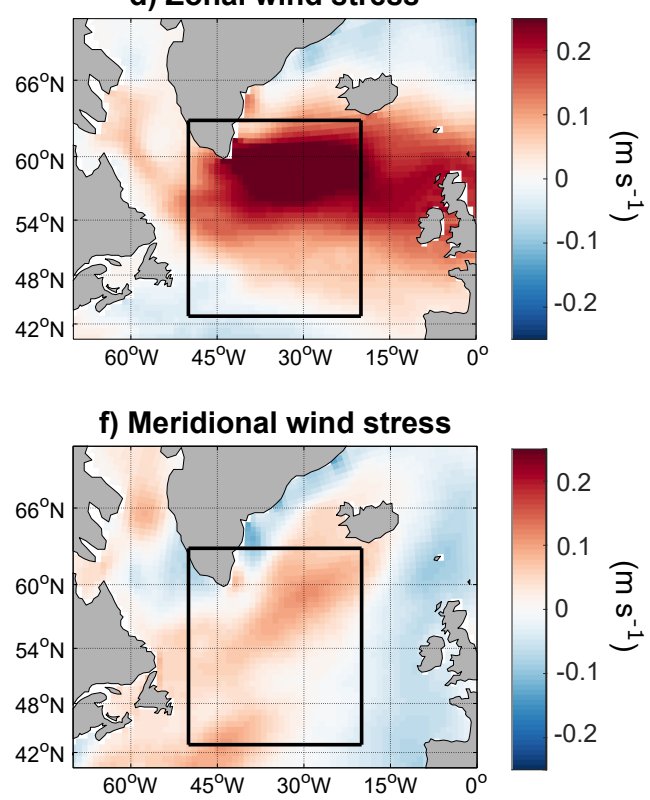

h) Mixed layer depth

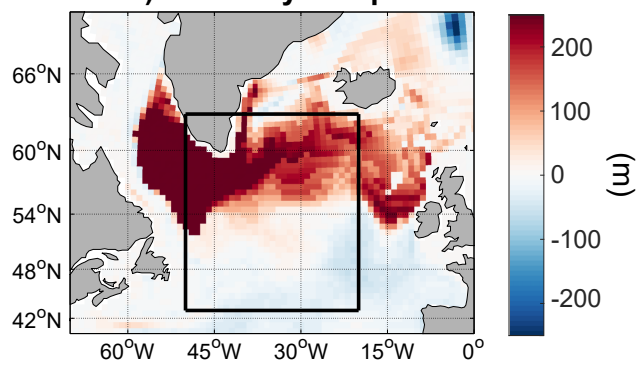

Figure A4. The spatial distribution of ECCOv4-r3 anomalies in the terms causing the initial anomalous surface cooling in December 2013 (left) and the same anomalies for January 2015 (right), when the net heat flux out of the surface was also high but its impact not seen in the temperature of the mixed layer. Shown are anomalies in a,b) the net surface heat flux $\left.\left(\mathrm{W} \mathrm{m}^{-2}\right), \mathrm{c}, \mathrm{d}\right)$ zonal wind stress $\left(\mathrm{m} \mathrm{s}^{-1}\right)$, e,f) meridional wind stress $\left(\mathrm{m} \mathrm{s}^{-1}\right)$, and MLD (m). 
https://doi.org/10.5194/os-2022-10

Preprint. Discussion started: 14 February 2022

(c) Author(s) 2022. CC BY 4.0 License.

\section{a) ECCOv4-r3}

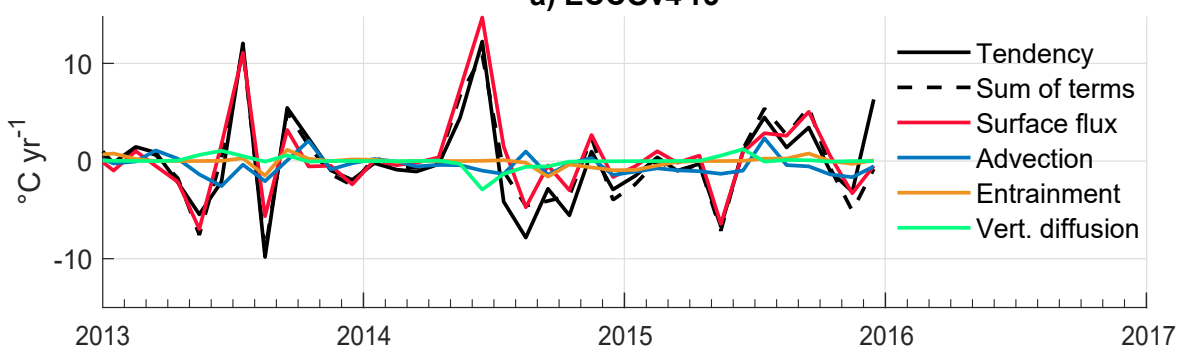

b) ECCOv4-r4

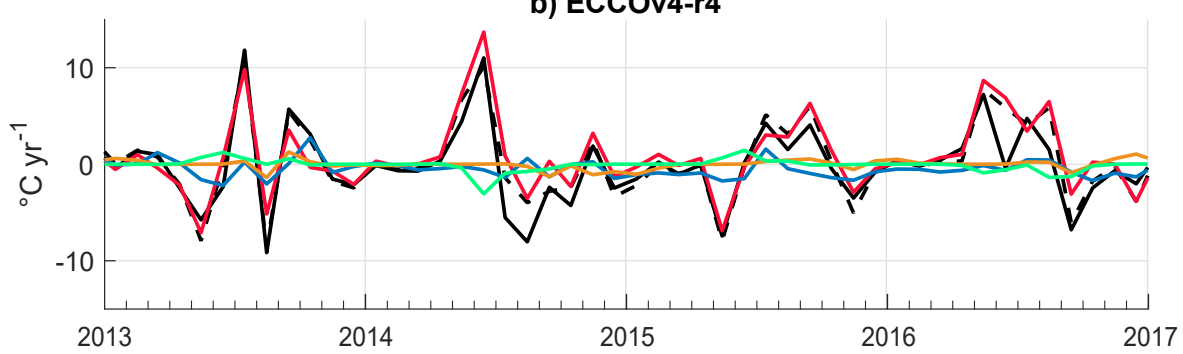

Figure A5. Anomalies in the dominant terms of the mixed layer temperature budget, relative to the $1992-2015$ monthly climatology $\left({ }^{\circ} \mathrm{C}\right.$ $\mathrm{yr}^{-1}$ ) for A) ECCOv4-r3 and B) ECCOv4-r4, averaged over the northeast of the North Atlantic (35-5 $\left.{ }^{\circ} \mathrm{W}, 53-63^{\circ} \mathrm{N}\right)$. Anomalies in the model temperature tendency are shown by the solid black line, and anomalies in the sum of the temperature budget terms driving the change in temperature by the dashed black line. The remaining lines represent those individual processes: the surface heat flux (red), horizontal advection (blue), vertical entrainment (orange), and vertical diffusion (green). 